\title{
Consolidación estructural del edificio patrimo- nial de C/Ripoll, 25 de Barcelona - Ca la Dona
}

\author{
Structural consolidation of the heritage building at 25th \\ Ripoll Street in Barcelona - Ca la Dona
}

S. Bestraten ${ }^{(*)}$, E. Hormias ${ }^{(* *)}$

\section{RESUMEN}

El edificio de la calle Ripoll $\mathrm{n}^{\circ} 25$ de Barcelona está catalogado por el Plan especial de protección del patrimonio arquitectónico del distrito barcelonés de Ciutat Vella.

En 2005 la asociación Ca la Dona con el apoyo de todas las administraciones públicas catalanas inicia un proceso de rehabilitación con criterios de sostenibilidad. Se realiza una intervención estructural innovadora consistente en una sustitución funcional de forjados existentes con panel de madera contralaminada, que en general no modifica el estado de cargas del edificio haciendo compatible la continuidad estructural de los muros de carga existentes.

Este proyecto abre un camino a la prefabricación en la rehabilitación arquitectónica, que permite su adaptación a los requerimientos normativos actuales y a su vez integra consideraciones tan actuales como la sostenibilidad.

\section{SUMMARY}

The building, found in 25th Ripoll Street, in Barcelona, is listed by the Special Plan for protection of architectural heritage of the Barcelona district, Ciutat Vella.

In 2005, the Ca la Dona association with support from all Catalan public administrations, starts a restoration process under a sustainability criteria. An innovative structural intervention is performed consisting in a functional replacement of the existing floorings with cross-laminated timber panel, which, doesn't change the overall load state of the building, making compatible the structural continuity of the existing load-bearing walls.

This project opens a way to the prefabrication of solutions used in architectural restoration, allowing to adapt to regulatory constraints, along with considering current issues, such as, sustainability.
Palabras clave: Rehabilitación; forjados; prefabricación; madera contralaminada; sostenibilidad.
Keywords: Restoration; floorings; prefabrication; cross-laminated timber; sustainability.

(*) ETSAB - Universitat Politècnica de Catalunya. Barcelona (España)

(**) EPSEB - Universitat Politècnica de Catalunya. Barcelona (España)

Persona de contacto/Corresponding author: sandra.bestraten@upc.edu (S. Bestraten) 
1. Emplazamiento del edificio de estudio en el barrio de Ciutat Vella de Barcelona.

2. Imagen del acueducto romano en el edificio colindante, plaza del 8 de Marzo. Se identifica el tramo de fachada ejecutado con paneles de madera contralaminada.

3. Planta primera del edificio previa a la intervención de la consolidación estructural.

4. Situación en planta baja del conjunto de arcos de piedra medievales y cerámicos de épocas posteriores. También se identifica el acueducto romano.

5. Diagnosis de las patologías en fachadas.

\section{CONTEXTO ACTUAL DE LA REHABILITACIÓN DE EDIFICIOS}

En los criterios de intervención integral aplicados a forjados de madera en edificios existentes hay una tendencia importante hacia la sustitución funcional o total de forjados con losas de hormigón armado o estructuras de acero y chapa colaborante (1). En los casos en los que se intenta conservar los forjados existentes estos se suelen reforzar con capas de compresión de hormigón conectadas a las vigas de madera (2).

Estos criterios estan motivados por la dificultad de diagnosticar el estado de conservación de este tipo de forjados, y también por los requerimientos de carga y deformación a que obligan la normativa actual. A estos aspectos hay que sumar características intrínsecas de la propia madera estructural que han condicionado su utilización: la limitación de las dimensiones de los troncos hasta hace pocas décadas, la presencia de nudos y otras singularidades propias del material, la dificultad de suministro, el control del ataque de los xilófagos y la estabilidad frente al fuego.

En la actualidad, la madera ha sido objeto de un proceso de industrialización que ofrece una gran variedad de productos, muchos de los cuáles con aplicabilidad en el refuerzo o sustitución funcional de forjados existentes. En esta línea cabe destacar la utilización de madera microlaminada como refuerzo de forjados en la rehabilitación del Palacio Pimentel y en un edificio

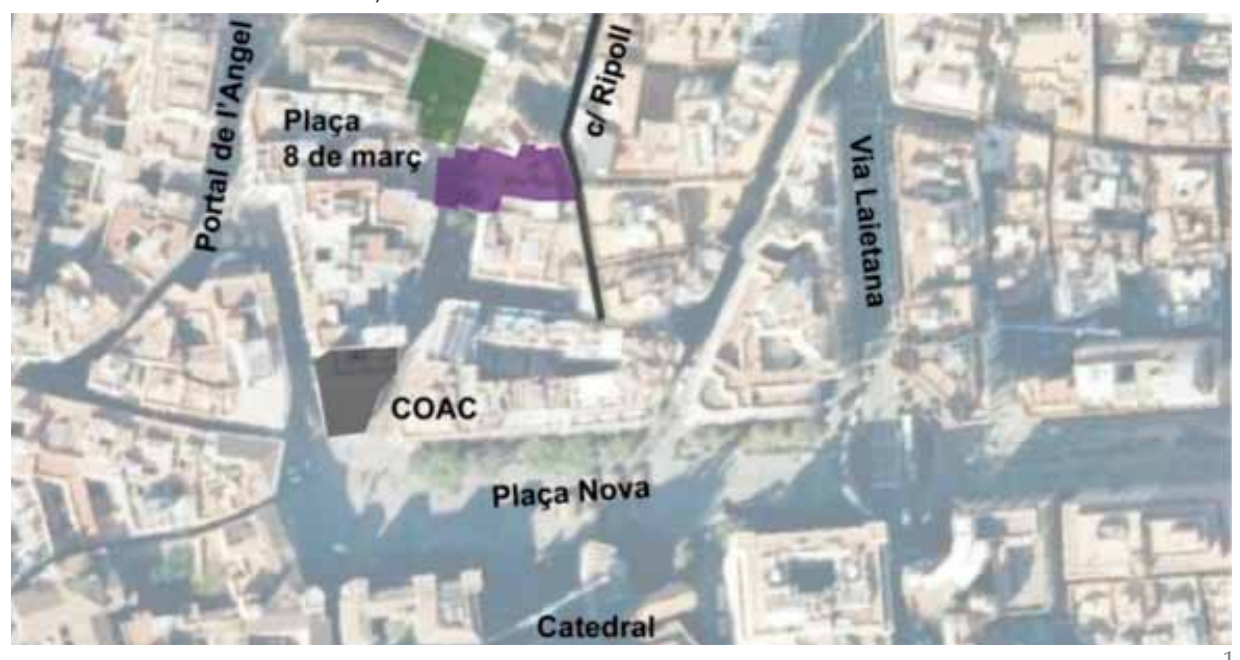

de Viviendas en el Pasaje Gutiérrez, ambos realizados en Valladolid por el Dr. Arquitecto Enrique Nuere Matauco (1).

La consolidación estructural del edificio de Ca la Dona en la Calle Ripoll 25 de Barcelona es una intervención innovadora en forjados de edificios existentes, consistente en una sustitución funcional con panel de madera contralaminada que permite conservar el estado de cargas del edificio y compatibiliza la continuidad estructural de los muros de carga existentes. Este último aspecto hace que el valor del edificio no se reduzca a su reutilización, sino que remarca su valor histórico y arquitectónico.

\section{ANTECEDENTES}

Desde 2005 la asociación feminista Ca la Dona ha estado trabajando, junto con un equipo de la Universidad Politécnica de Catalunya dirigido por la arquitecta Sandra Bestraten, en la definición del proyecto de rehabilitación de la nueva casa.

El proyecto de Ca la Dona parte del compromiso del feminismo con la sociedad, haciendo de su casa un referente en sostenibilidad y participación social. El valor del proyecto que aquí se presenta no está sólo en el esfuerzo tecnológico de la intervención, sino también en el valor intangible de los 6 años de proceso participativo de género como herramienta transformadora y proyectual.

\section{APROXIMACIÓN HISTÓRICA AL EDIFICIO DE LA CALLE RIPOLL 25} 25, aledaña a la Plaza Nova, junto a la Catedral de Barcelona (Figura 1). La edificación está catalogada en el nivel C (Bien con elementos de interés) en el Plan especial de protección del patrimonio arquitectónico del distrito de Ciutat Vella.
El edificio está situado en la calle Ripoll $n^{\circ}$

El valor histórico del edificio retrocede hasta época romana. Se han descubierto 4 arcadas del acueducto romano (Figura 2) y en el interior del equipamiento se han haIlado los cimientos de dos pilastras (3) y la sección constructiva del vaso (4). También son de época romana los restos de un tramo de la calzada de acceso a la ciudad de Barcino (5). 


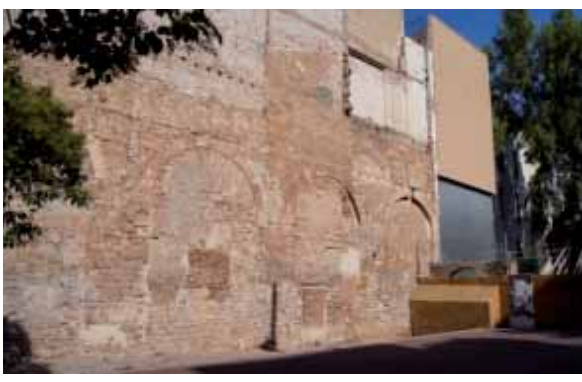

En el siglo XI-XIII, nace el primer barrio extramurallas conocido como la Vilanova dels Arcs, donde las casas se adosaban al acueducto, originando la finca de estudio. Aún así, también se han datado unos muros del siglo IX, época de la cual no se habían encontrado estructuras construidas fuera de murallas en Barcelona (5). Entre los siglos XVI i XIX se suceden diferentes ampliaciones y reformas que configuran el edificio a rehabilitar.

\section{DESCRIPCIÓN DEL EDIFICIO EXISTENTE}

El edificio existente está formado por cuatro plantas (baja, principal, primera y segunda). Una de las características principales del edificio es el gran desarrollo de fachada, $73 \mathrm{~m}$ lineales, que le dota de gran luminosidad, siendo escepcional en un edificio de Ciutat Vella en Barcelona, cuando la crujía de la parcela en la fachada de la calle Ripoll es de sólo 17,8 m. Esto es posible gracias a la existencia de un pasaje y un jardín del siglo XIX en planta principal, en origen interior de manzana, y hoy totalmente abierto por tres de sus cuatro caras. A estas fachadas hay que añadir la existencia de un patio de luces de $14 \mathrm{~m}^{2}(5 \times 4 \mathrm{~m})$.

El uso del edificio en planta baja era de varios locales y el resto de plantas se distribuían en cinco viviendas por rellano de configuración bastante tortuosa, a las que se accede desde una caja de escalera próxima a la fachada de Ripoll 25 (Figura 3). La cubierta del edificio en general era inclinada con teja árabe, a excepción de las crujías que dan a la calle Ripoll, donde existía una cubierta a la catalana.

La compleja historia evolutiva del edificio se traduce en una gran heterogeneidad de soluciones constructivas tanto en forjados como en elementos verticales de carga.

La estructura vertical de la planta baja y principal está formada por muros de mampostería de piedra y algunos paños de tapia de origen medieval. La planta baja además, presenta pilastras y arcos de piedra medievales (s.XIII) y de ladrillo macizo del siglo XIX (Figura 4). Las remuntas de las plantas primera y segunda se realizan en ladrillo macizo manual de $15 \mathrm{~cm}$ de espesor. La cimentación en general es la original del edificio medieval de dos plantas, con muy poca profundidad, en general no superiores a $30 \mathrm{~cm}$.
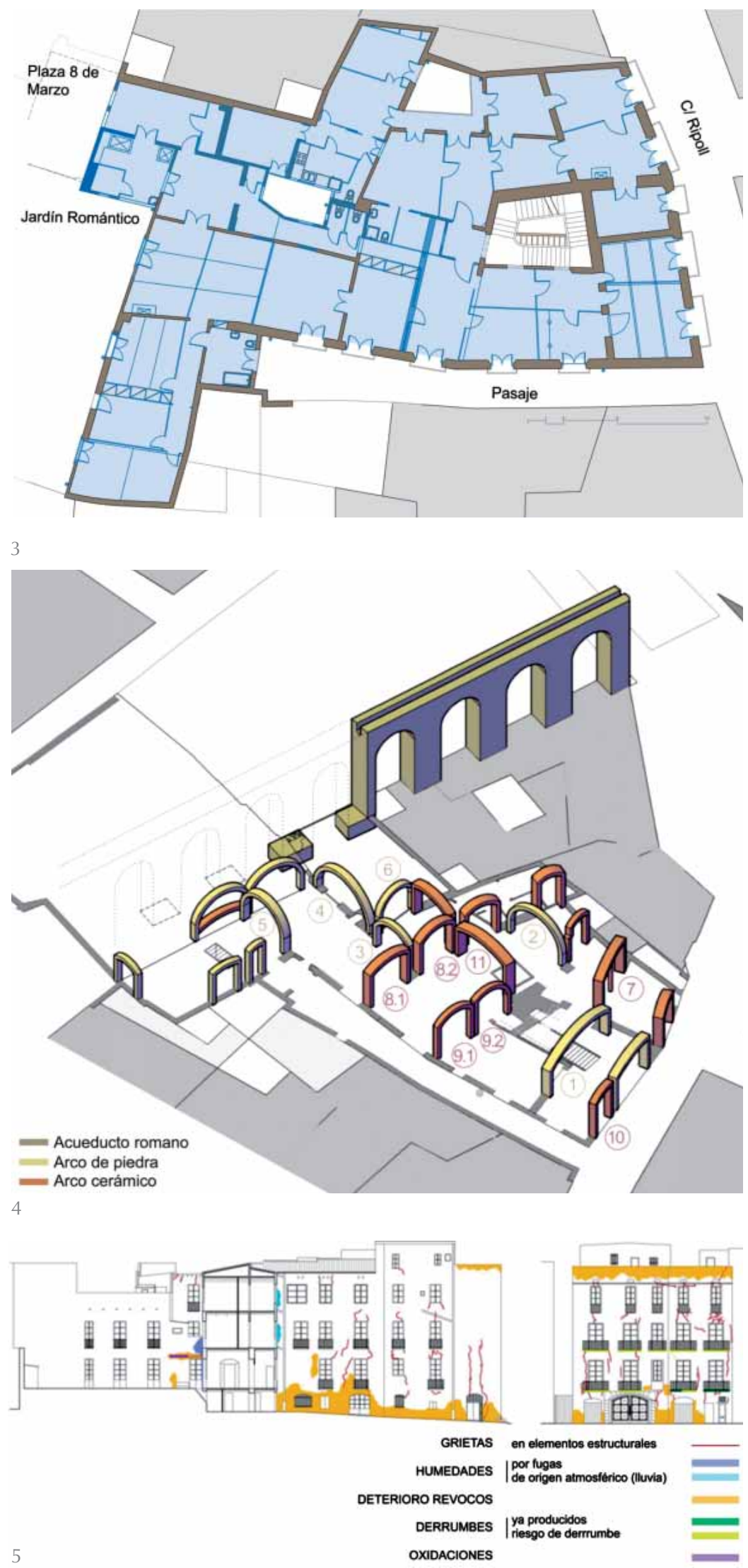
6. Estructura del techo de la planta baja donde se identifican las diferentes tipologías de forjados y las principales lesiones.
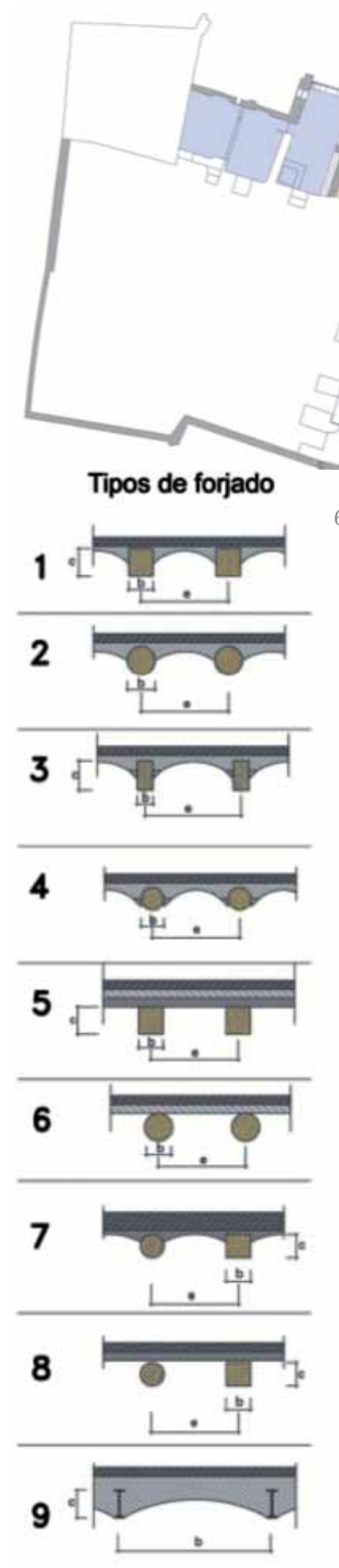

La estructura horizontal está formada principalmente por forjados de madera con hasta 9 soluciones de forjado diferentes fruto del diferente origen tanto espacial como temporal de los mismos (Figura 5). Encontramos forjados de madera con bovedillas cerámicas, forjados de madera con artesonados y forjados de viguetas metálicas. Algunos de los forjados de madera presentaban refuerzos metálicos, resueltos normalmente con parteluces. En la planta primera algunos forjados presentaban desniveles e inclinaciones, debido a su función de cubierta en algún momento de su historia.

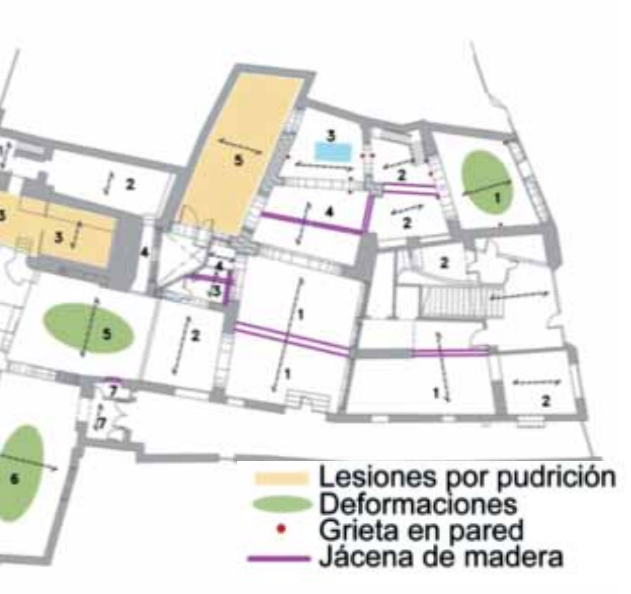

\section{DIAGNOSIS ESTRUCTURAL}

Desde un punto de vista estructural el edificio presenta problemas importantes tanto en muros como en forjados.

El núcleo de escalera es una amalgama de soluciones constructivas en mampostería de piedra, tapia y ladrillo macizo que, por su génesis distanciada en los siglos, en alguna de sus esquinas no estan trabadas. La debilidad de la caja se ha visto afectada por el empuje de las bóvedas de la escalera, que ha provocado la aparición de grietas tanto en muros como bóvedas. En el siglo XX, las bóvedas de escalera se refuerzan con perfiles metálicos curvados que no resuelven el problema de los muros, dado que no se rigidizó el núcleo de escalera. La fachada de la calle Ripoll presenta desplomes de más de $15 \mathrm{~cm}$ entre planta baja y cubierta y grietas estructurales, provocados por la combinación de la solución de cimentación excasa y el empuje de la caja de escalera (Figura 5).

Los arcos de medio punto de piedra medievales de planta baja en general estaban en buen estado. En cambio los arcos rebajados de ladrillo decimonónicos presentaban fisuras o descuelgues.
Los forjados de madera, en general se encontraban afectados por xilófagos (carcoma grande y termita) y pudriciones por hongos en las zonas donde había filtraciones de agua de lluvia. La mayor parte de los refuerzos metálicos de las viguetas presentaban estados avanzados de corrosión, destacando que aquellas salas que tenían forjados más recientes de perfil metálico eran los que presentaban mayor nivel de degradación debido a la presencia de filtraciones de agua que prácticamente habían desmaterializado los perfiles (6).

El peritaje estructural de los forjados de madera concluye que la mayor parte de los mismos no cumple normativa por criterios de deformación y muchos tampoco por resistencia. En el caso de proponer un cambio de uso del edificio a equipamiento con unos requerimientos más restrictivos a nivel de sobrecargas se hace necesario la rehabilitación integral de toda la estructura horizontal (Figura 6).

En relación a lesiones físicas, el edificio presenta muestras de humedades en casi todas las zona cercanas a los patios y en los forjados bajo cubierta.

\section{PROPUESTA DE CONSOLIDACIÓN ESTRUCTURAL DE FORJADOS}

\subsection{Integración de un sistema industriali- zado y sostenible en rehabilitación}

Entre los retos que la rehabilitación de la edificación existente debe abordar destaca la necesidad de incorporar criterios de sostenibilidad sólidos y la utilización de soluciones industrializadas. Éstos han sido incorporados en la consolidación estructural de Ca la Dona, gracias al panel de madera contralaminada (de la empresa KLH). La solución adoptada cumple con los requisitos propios de la prefabricación convencional la optimización de los tiempos de producción y ejecución con un montaje en seco rápido y limpio (2), que a su vez mejora las condiciones de seguridad durante la realización de las obras. A su vez, aporta nuevos valores añadidos como el patronaje abierto, posible gracias a la informatización del corte en fábrica sin necesidad de amortizar moldes. La industrialización abierta propuesta permite diversidad infinita de medidas de piezas, incluso posibles ajustes en la obra y modificaciones estructurales durante la vida útil del edificio, ofreciendo un modelo de futuro: La prefabricación flexible.

La madera contralaminada se compone de láminas de pino o abeto estratificadas bidireccionalmente de forma alterna. Las 
láminas se encolan y se prensan a gran presión en fábrica, obteniendo como resultado placas de madera maciza de gran formato. Mediante la colocación cruzada de estas capas longitudinales y transversales, los coeficientes de contracción y dilatación se reducen y se incrementa la resistencia y la estabilidad estática. En la consolidación estructural de Ca la Dona la madera utilizada ha sido el pino, porque permite $3 \mathrm{~mm}$ de penetración del tratamiento superficial fungicida por pulverización, mucho más elevada que $1 \mathrm{~mm}$ que admite el abeto.

Hay que remarcar que la madera contralaminada es un material de bajo impacto ambiental. Este aspecto permite reducir las emisiones de $\mathrm{CO} 2$, del orden del $77 \%$ respecto las soluciones convencionales de sustitución estructural funcional utilizadas habitualmente (forjados con chapa colaborante o losa de hormigón).

El proceso de industrialización comienza con la difícil tarea de hacer previamente un levantamiento preciso de la totalidad de las salas del edificio. A continuación se define el despiece más adecuado en función de los requisitos estructurales y el proceso de montaje previsto. La información gráfica es digitalizada y se envía a fábrica donde se cortan con sistemas informatizados de mecanización todas las piezas con las medidas exactas de cada sala. Finalmente se aplican los tratamientos fungicidas correspondientes mediante pulverización también en fábrica. Los paneles se trasladan a obra en camiones y llegan ordenados en series según el orden de montaje previamente establecido. En paralelo a la producción en fábrica, en obra se colocan los angulares metálicos de acero galvanizado tipo $L$ donde se han de apoyar los paneles de madera contralaminada, al tiempo que se realizan el resto de los trabajos de consolidación de elementos estructurales (cimentación, muros de carga, arcos o dinteles), así como los trabajos de excavación arqueológica, estos últimos difíciles de compaginar en una obra de refuerzo convencional con apuntalamientos generalizados.

\subsection{El panel de madera contralaminada como solución material de los forjados}

El planteamiento inicial previsto en el proyecto ejecutivo responde a la pretensión de utilizar una solución constructiva ligera basada en la madera contralaminada como refuerzo activo integral en colaboración con las viguetas existentes. La conexión con el muro se asume con el empotramiento de las vigas existentes y las escuadras puntuales por la parte superior. Este sistema tiene el reto de añadir un encaje que defina un pla- no horizontal para conectar de forma homogenea el panel de madera contralaminada con todas las vigas existentes, dada la diferente flecha de cada una de ellas (Figura 7).

Finalmente el resultado de la diagnosis de forjados existentes recomienda la sustitución funcional de forjados, que se realiza utilizando paneles de madera contralaminada como material de forjar (Figura 8).

En la rehabilitación que se presenta se ha trabajado con paneles de 1,2 m de ancho, la mitad del ancho de un panel estándar $(2,45 \mathrm{~m})$, para optimizar el corte en fábrica y a su vez, garantizar su movilidad y manipulación entre las salas del edificio existente. Las longitudes utilizadas son las propias de las luces de cada sala y los espesores han sido de $202 \mathrm{~mm}$ para luces inferiores a $5,3 \mathrm{~m}$ y $245 \mathrm{~mm}$ para luces inferiores a 6,5 m. Concretamente, en esta obra se han colocado 272 paneles, cada uno de ellos con medidas de longitud y ancho propias, con encajes a media madera entre paneles que tienen una ubicación específica y única en la estructura del edificio (Figuras 9,10,11 y 12).
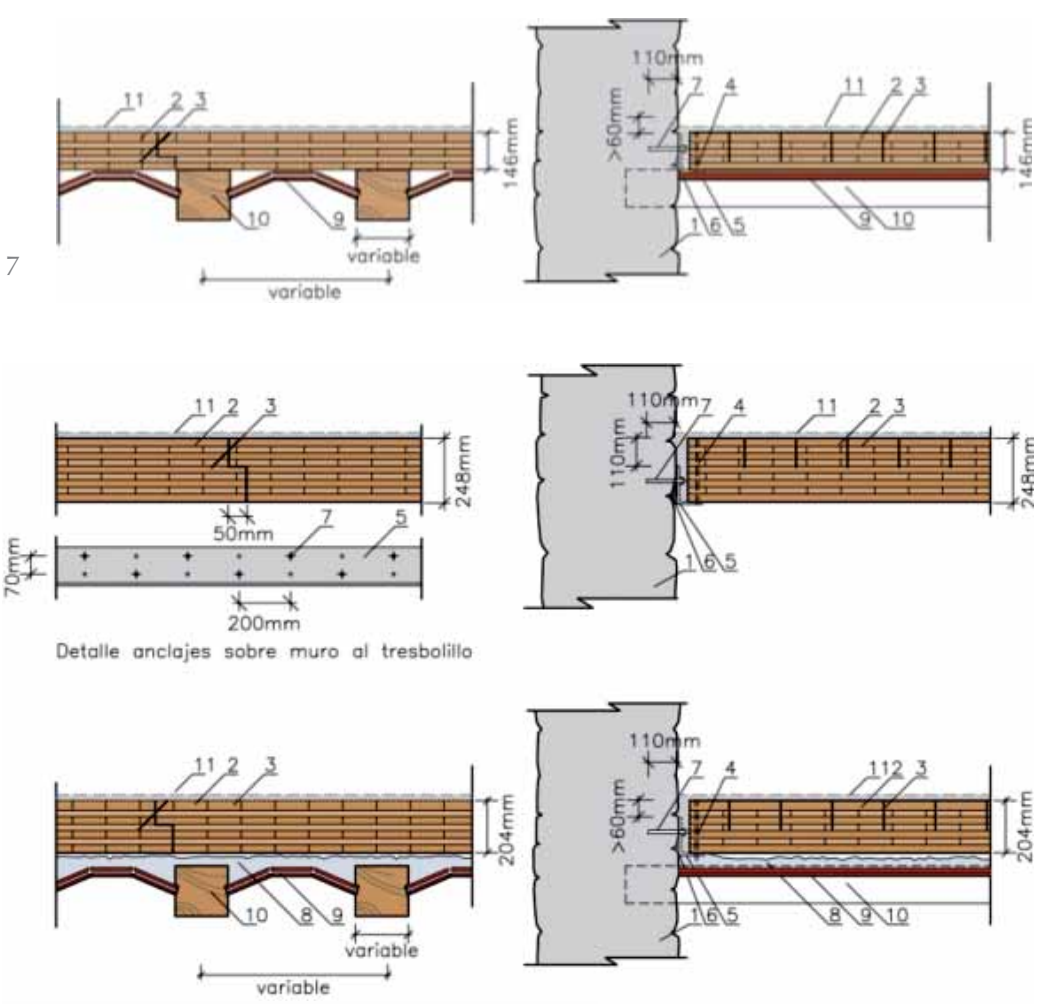

1. Muro existente

2. Panel de madera contralaminada KLH e min. $204 \mathrm{~mm}$

El90

3. Junta de panel: tirafondo $5 / 1601 \mathrm{c} / 20 \mathrm{~cm}$

4. Union panel-perfil: pasador autotaladrante SFS WS-T Ø7

$1 \mathrm{c} / 60 \mathrm{~cm}$

5. Perfil $L$ 150.90.10 galvanizado

6. Retacado con mortero de resinas

7. Anclaje en muro $\mathrm{c} / 20 \mathrm{~cm}$ a tresbolillo: HIT RE500+Varilla

HAS-E M120

8. Proyección de perlita-vermiculita e min. $3 \mathrm{~cm} \mathrm{El} 90$

9. Bovedilla existente

10. Viga de madera de forjado existente tratada con

fungicida por inyección

fungicida por inyección

8
7. Detalle constructivo de la pro-
puesta de la solución de forjado
según proyecto ejecutivo, donde
el panel de madera contralami-
nada actúa como refuerzo del
forjado existente.
8. Detalle constructivo de las dos
principales soluciones de forjado
realizadas en Ca la Dona. Tanto si
se mantiene o no el forjado exis-
tente de madera, la función por-
tante la asumen los nuevos pane-
les de madera contralaminada. 

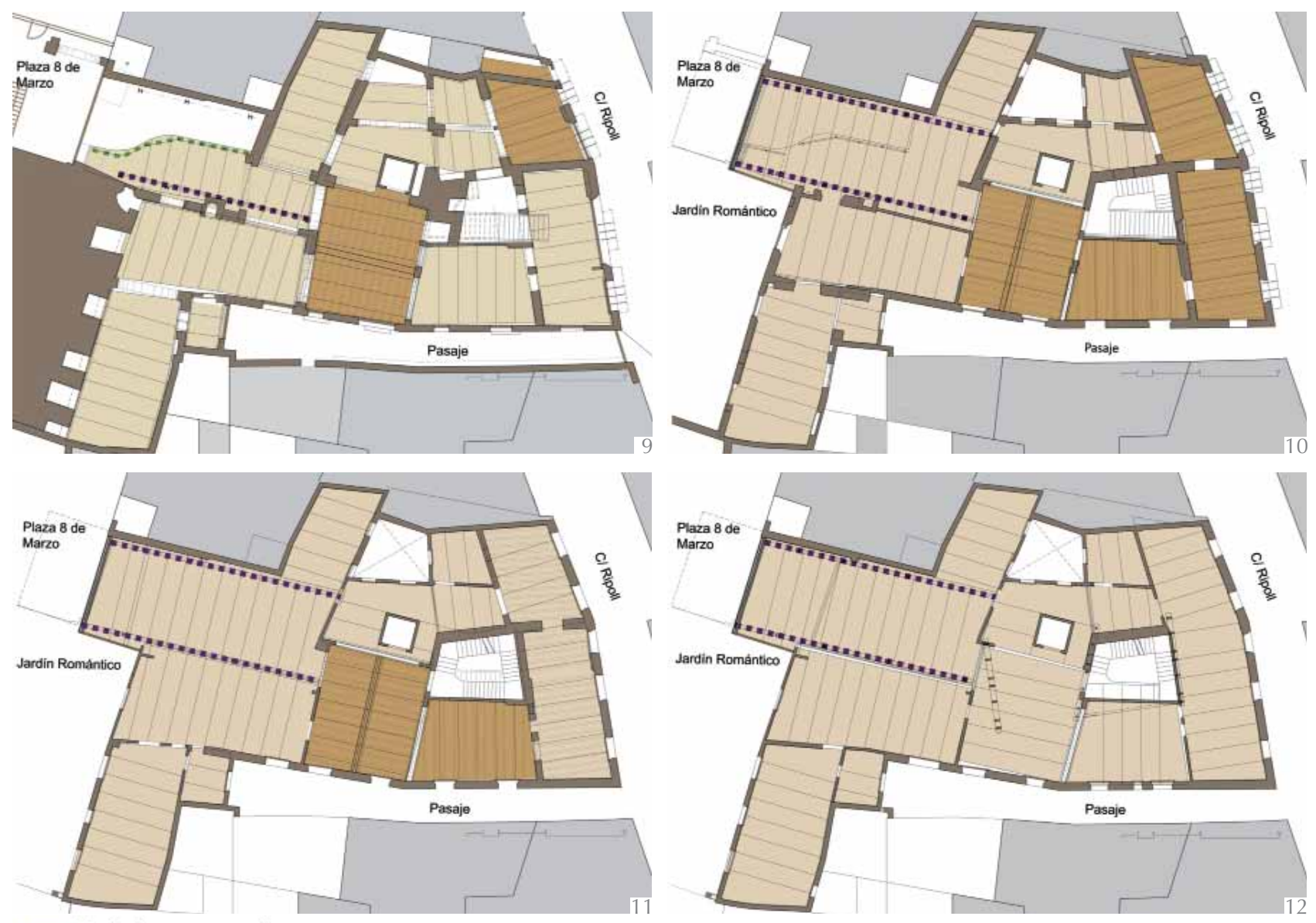

Forjado conservado

Substitución de forjado

- Apoyo sobre jácena " = = Colgado con tensores

9. Planta estructura con el despiece de paneles de madera contralaminada, techo de la planta baja.

10. Planta estructura con el despiece de paneles de madera contralaminada, techo de la planta principal.

11. Planta estructura con el despiece de paneles de madera contralaminada, techo de la planta primera.

12. Planta estructura con el despiece de paneles de madera contralaminada, techo de la planta segunda.

13. Cuadro comparativo de las cargas que se transmiten a la fachada de la calle Ripoll de las diferentes opciones de forjados, considerando el peso propio y las sobrecargas de uso.
La ventaja del material respecto a otros productos de construcción con madera se encuentra en la capacidad de transmitir cargas bidireccionalemente gracias al encaje a media madera entre paneles y la conexión entre ellas mediante tirafondos 5/160 cada $20 \mathrm{~cm}$ colocados con una inclinación de $45^{\circ}$ (Figura 8). Esta solución produce un efecto placa que aporta un mayor grado de estabilidad, no sólo frente a acciones estáticas, sino también dinámicas. En el caso de estas últimas, el refuerzo de la conexión entre el forjado y el muro es la acción más eficaz en la mejora del comportamiento sísmico global del edificio (7) (8) (9).
La solución aplicada en rehabilitación hace compatible que los muros estructurales originales del edificio sigan asumiendo su función portante gracias a la ligereza de los nuevos forjados con un peso de 1,02 KN/ $\mathrm{m}^{2}$, los de $202 \mathrm{~mm}$ de espesor y de 1,24 $\mathrm{KN} / \mathrm{m}^{2}$, para los de $248 \mathrm{~mm}$. Se ha procurado que el estado de cargas permanentes sea lo más similar posible al estado de cargas original del edificio, quedando los pesos propios de los forjados reducidos en un $4 \%$ con respecto a su peso original. Sin embargo, existe un incremento considerable en las sobrecargas de uso (de $2 \mathrm{KN} / \mathrm{m}^{2}$ a $5 \mathrm{KN}$ / $\mathrm{m}^{2}$ ) que condiciona el canto de forjado pro-

\begin{tabular}{|c|c|c|c|}
\hline \multicolumn{4}{|c|}{ Cargas de forjados sobre fachada calle Ripoll } \\
\hline \multicolumn{4}{|c|}{ Peso propio forjados } \\
\hline $\begin{array}{l}\text { Estado previo } \\
2,70 \mathrm{kN} / \mathrm{m}_{2}\end{array}$ & $\begin{array}{c}\text { Madera Contralaminada } \\
\qquad=248 \mathrm{~mm}\end{array}$ & $\begin{array}{l}\text { Forjado colaborante } \\
\text { e-120mm, + shestructura } \\
250 \mathrm{kN} / \mathrm{m}^{2}\end{array}$ & $\begin{array}{l}\text { Losa de hormigón armado } \\
\text { e=200mm }\end{array}$ \\
\hline $2,70 \mathrm{kN} / \mathrm{m} 2$ & $1,24 \mathrm{kN} / \mathrm{m} 2$ & $2,50 \mathrm{kN} / \mathrm{m} 2$ & $5,00 \mathrm{kN} / \mathrm{m} 2$ \\
\hline \multicolumn{4}{|c|}{ Peso propio y cargas permanentes sobre muro (cargas permanentes: $1,5 \mathrm{kN} / \mathrm{m}^{3}$ ) } \\
\hline $5,54 \mathrm{kN} / \mathrm{ml}$ & $\begin{array}{c}5,62 \mathrm{kN} / \mathrm{ml} \\
+1,489 \%\end{array}$ & $\begin{array}{c}8,20 \mathrm{kN} / \mathrm{ml} \\
+48,15 \mathrm{~s}\end{array}$ & $\begin{array}{c}\mathbf{1 3 , 3 3} \mathbf{k N} / \mathrm{ml} \\
+140,7496\end{array}$ \\
\hline \multicolumn{4}{|c|}{ Cargas Globales sobre muro (sobrecarga de uso estado inicial: $2 \mathrm{kN} / \mathrm{m}^{2}$; estado final: $5 \mathrm{kn} / \mathrm{m}^{2}$ ) } \\
\hline $9,64 \mathrm{kN} / \mathrm{ml}$ & $\begin{array}{c}15,87 \mathrm{kN} / \mathrm{ml} \\
+64,68 \mathrm{~K}\end{array}$ & $\begin{array}{c}18,45 \mathrm{kN} / \mathrm{ml} \\
+91,49 \mathrm{~W}\end{array}$ & $\begin{array}{c}23,58 \mathrm{kN} / \mathrm{ml} \\
+144,68 \%\end{array}$ \\
\hline
\end{tabular}




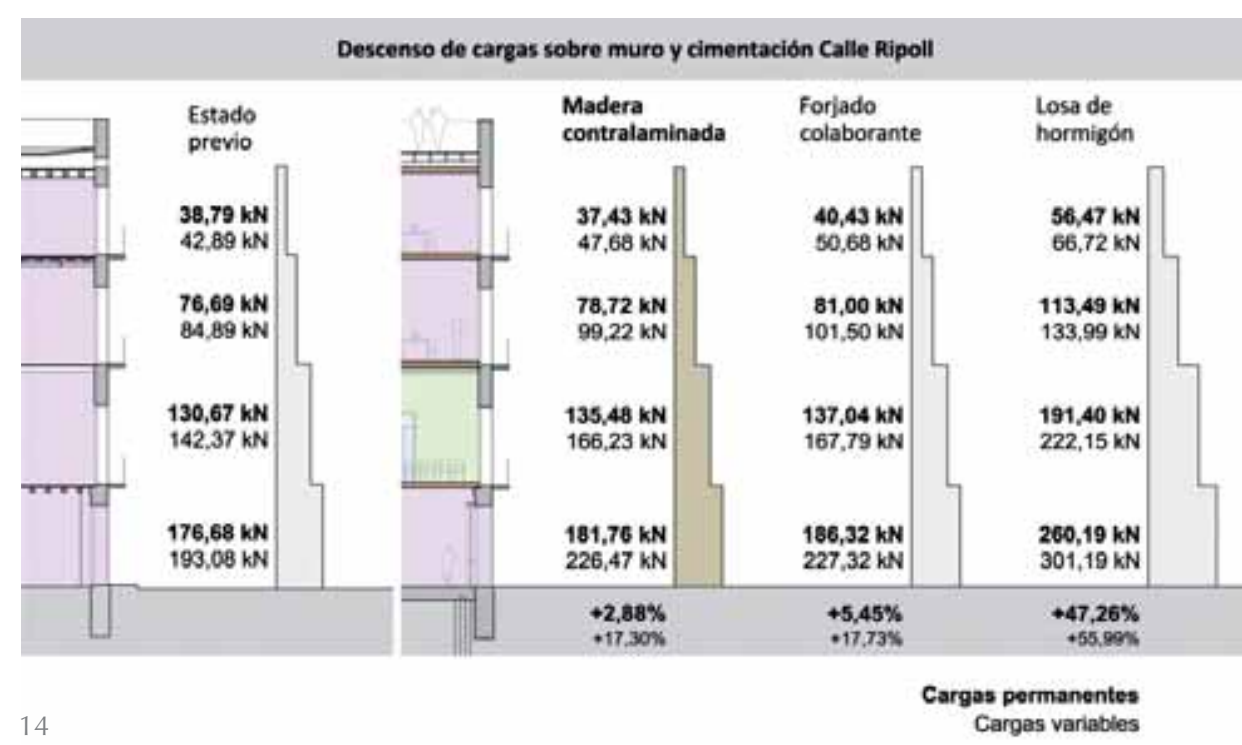

puesto y el refuerzo realizado en los muros de carga y en la cimentación (Figura 13).

En el caso concreto de la fachada de la caIle Ripoll tenemos dos forjados en los que se ha mantenido el forjado de madera inferior existente, y dos forjados formados únicamente por los tableros de madera contralaminada. Tal como se puede ver en la Figura 14, se ha comparado el estado de cargas resultante con las paredes de un forjado colaborante de $12 \mathrm{~cm}$ de espesor con su correspondiente subestructura metálica $\left(2,5 \mathrm{kN} / \mathrm{m}^{2}\right)$ y con una losa de hormigón armado de $20 \mathrm{~cm}$ de espesor $\left(5 \mathrm{kN} / \mathrm{m}^{2}\right)$. En ninguna de estas dos últimas soluciones se ha considerado la posible sobrecarga de mantener el forjado existente. Podemos observar que mientras los forjados de madera y metálicos conservan unas cargas similares respecto al estado previo, pues se sustituye el peso del pavimento y el relleno por el nuevo forjado, los forjados realizados únicamente con hormigón aumentan entre un $45 \%$ y un $55 \%$ el peso de las cargas a cimientos. Cabe destacar, que el caso de la fachada estudiada, la variación de sobrecargas en los forjados se ve atenuada por la carga permanente que representa el muro de piedra. En los casos en qué los muros son más ligeros y estrechos, estas variaciones entre los diferentes materiales aumentan exponencialmente.

Es de remarcar la solución adoptada en el doble espacio del acceso por la Plaza del 8 de marzo, donde se encuentran los cimientos del acueducto romano. El forjado intermedio del vestíbulo está colgado de una línea de cables tensados cada 1,5 -2 metros que se ancla en el forjado superior mediante unas pletinas continuas que reparten las cargas puntuales a lo largo de todos los paneles de madera. Para garantizar su estabilidad frente al fuego, los cables de acero de $20 \mathrm{~mm}$ están enfundados por un tubo metálico relleno de hormigón fluido (Figuras 15,16 y 17 ).

\subsection{Apoyo de los forjados en el muro}

La conexión de los paneles a la estructura vertical, se resuelve con perfiles de acero galvanizado longitudinales en L 150.90.10 de 2 metros de longitud. Esta solución permite deslizar las placas de madera a lo largo de los perfiles para agilizar el montaje y ajustar su posición.

La colocación de los anclajes debe estar lo más próximo a los forjados existentes para que el aumento de la cota de cada forjado se limite al canto del mismo y minimizar el desnivel en los encuentros con los niveles de la escalera patrimonial y los balcones de fachada.

La posición óptima del perfil de apoyo se consigue colocando el ala horizontal en la parte superior para poder aprovechar el máximo de superficie de apoyo $90 \mathrm{~mm}$ e incluso poder realizar el control de calidad de los tacos de conexión al muro desde la parte inferior. Otra ventaja que permite la colocación en este sentido es tomar medidas de los paneles directamente de las salas, sin necesidad de esperar a tener colocados los angulares.

Pero la posición de los perfiles en $\mathrm{L}$ de apoyo de los paneles está condicionado al mantenimiento o eliminación del forjado preexistente. Por norma general, a pesar de tener forjados afectados, se procedió a colocar el angular con el ala en la parte inferior para poder realizar el derribo de los forjados afectados después, una vez colocado el nuevo forjado de paneles contralaminados. Este hecho permite que el edificio no quede tan desarriostrado en el proceso de
14. Esquema comparativo de transmisión vertical de cargas en fachada principal de la calle Ripoll, considerando el incremento de cargas permanentes y sobrecargas variables de uso en el cimiento.

15 y 16. Vestíbulo de acceso junto al acueducto, con el forjado de paneles de madera contralaminada de la planta principal colgado mediante tirantes de la planta superior.

17. Detalle constructivo del forjado de planta principal colgado mediante tirantes de la planta superior.

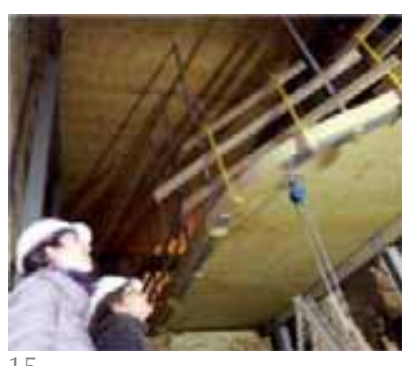

15
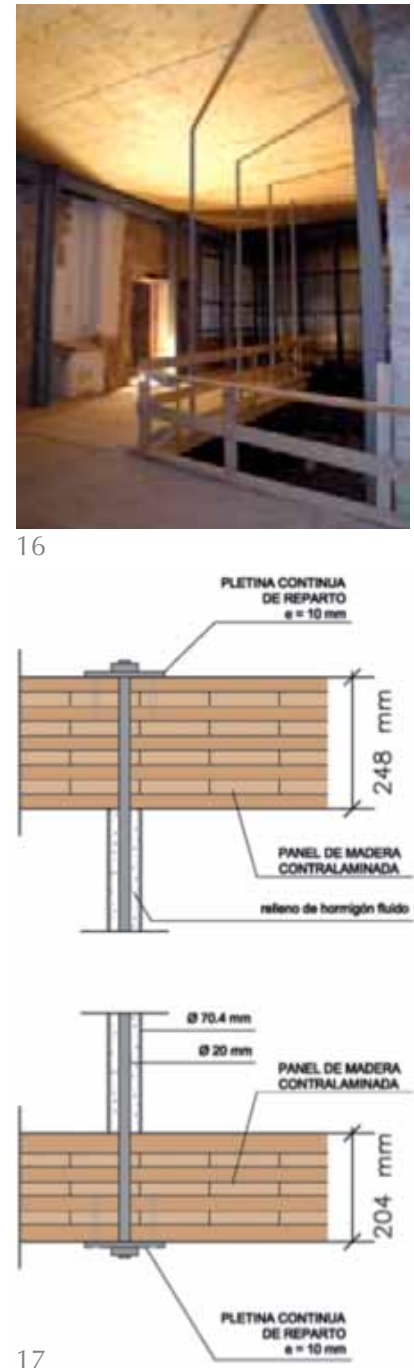
18. Ensayo a tracción de anclajes HILTI de conexión de angular a muro. El valor establecido de resistencia al arrancamiento es de 800 kN. Se ensayaron el 50\% de los anclajes.

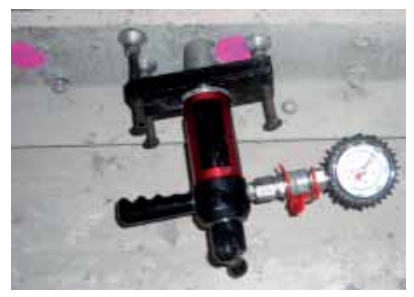

18 consolidación estructural. El inconveniente que implica la colocación de la L con el ala horizontal en la parte inferior es la necesidad de tomar medidas de las salas una vez colocados los angulares. También se ve disminuida la superficie de apoyo ya que la tuerca de los tacos de anclaje al muro hacen reducir $20 \mathrm{~mm}$ de apoyo. Se tomó como criterio mínimo de soporte $40 \mathrm{~mm}$, aun siendo habitualmente $60 \mathrm{~mm}$ la profundidad de apoyo. Cabe destacar que el control de calidad de los anclajes implica que se realice previo a la colocación de los paneles (Figura 18).

La fijación de los perfiles al soporte vertical se realiza mediante tacos químicos Hilti HIT RE500+varilla HAS-E M12. Para el cálculo del número de tacos necesarios, se llevaron a cabo previamente pruebas de resistencia a extracción de los muros. En el edificio de Ripoll 25, los muros en los que apoyan los nuevos forjados son de distintos tipos de obra de fábrica de ladrillo macizo y piedra. La heterogeneidad del soporte, implica la colocación lineal de un taco cada $20 \mathrm{~cm}$, dispuestos entre sí al tresbolillo. Tras la colocación de los tacos, se realizaron ensayos de tracción sobre el $50 \%$ de los anclajes comprobando que la resistencia al arrancamiento fuera siempre superior a la establecida de $800 \mathrm{kN}$ (Figura 18).

El mecanizado de los perfiles en L para la fijación de los tacos debe permitir el ajuste del perfil durante el replanteo de su posición. Para ello es necesario que en los agujeros de los extremos se realice un coliso que permita evitar la fijación del primer taco en una irregularidad del soporte, por ejemplo en el caso de una junta o de un árido extremadamente duro. Aunque la colocación de los tacos es al tresbolillo, el mecanizado debe realizarse cada $20 \mathrm{~cm}$ tanto en la hilera superior como en la inferior. Esto permite garantizar que en caso de encontrar una deficiencia en un taco al realizar el control de calidad, se pueda reforzar ese punto colocando un nuevo taco en el agujero superior o inferior.

Finalmente, en la colocación y fijación del perfil con el soporte vertical para conseguir el contacto de toda la superficie del ala del perfil con el muro, una vez colocado el perfil previo repicado del revoco, se realiza un sellado para poder retacar a continuación con un mortero fluido Sikagrout. Excepcionalmente algún perfil presentaba pequeños desnivelados de entre 2 y $4 \mathrm{~mm}$. Para garantizar la horizontalidad y el reparto lineal de cargas en todo el perfil metálico, se realizó un retacado con Sikabond que ofrecia adaptabilidad al desnivel, suficiente resistencia mecánica y una fluidez controlada.

\subsection{Respuesta a los requerimientos normativos}

Ineludiblemente, la solución responde a los requerimientos normativos establecidos para el uso del edificio, en especial los estructurales y los de incendio (10).

La comprobación del cálculo a flexión de los paneles de madera contralaminada se ha realizado mediante la consideración de los paneles como vigas biarticuladas en ambos extremos. En la sección de estas vigas, tan sólo se consideran en el cálculo las capas con fibras paralelas a los esfuerzos de tracción y compresión inducidos por el momento flector, pues la dirección de las fibras varía en función de las capas a lo largo de la sección. Por tanto, nos encontramos por el lado de la seguridad despreciando la colaboración de las fibras perpendiculares a los esfuerzos.

En el cálculo de Estados Límites Últimos, se ha comprobado que la tensión admisible a flexión $\left(f_{m k}\right.$ ) propia del material establecida según el DITE ETA-06-0138 es inferior a la tensión de solicitación del momento flector en el centro de la barra.

En el caso de la losa de 202 mm se comprueba que:

Tensión resistente: $\mathrm{f}_{\mathrm{m}, \mathrm{d}}$

$\mathrm{f}_{\mathrm{m}, \mathrm{d}}=\mathrm{k}_{\mathrm{mod}} \cdot\left(\mathrm{f}_{\mathrm{m}, \mathrm{k}} / \gamma_{\mathrm{m}}\right)=0,9 \cdot(24 / 1,25)==$ $17,28 \mathrm{~N} / \mathrm{mm}^{2}$

Momento de diseño:

$M_{d}=Q^{2} / 8=10,21 \cdot 5,32 / 8=35,86 \mathrm{kNm}$

Inercia neta de la sección sin considerar fibras en la dirección transversal:

$\mathrm{I}_{\text {neta }}=\mathrm{I}_{1}+\mathrm{I}_{2}+\ldots .+\mathrm{I}_{\mathrm{x}}+\mathrm{A}\left(\mathrm{d}_{1}\right)^{2}+\mathrm{A}\left(\mathrm{d}_{2}\right)^{2}+\ldots .+$

$\mathrm{A}\left(\mathrm{d}_{\mathrm{x}}\right)^{2}=\left(1000 \cdot 34^{3 / 12}\right) \cdot 4+\left(34000 \cdot 107^{2}\right) \cdot 4$

$+\left(34000 \cdot 73^{2}\right) \cdot 4=546.223 .360 \mathrm{~mm}^{4}$

Módulo resistente neto:

$W_{\text {neto }}=2 \cdot I_{\text {neta }} / \mathrm{h}=2 \cdot 546.223 .360 / 202=$ $=5.408 .132 \mathrm{~mm}^{3}$

Tensión de diseño $(E L U)=$

$\mathrm{M} / \mathrm{W}=35,86 \cdot 106 \mathrm{kNm} / 5.408 .132 \mathrm{~mm}^{3}$ $=6,63 \mathrm{~N} / \mathrm{mm}^{2}$

En el cálculo de los Estados Límites de Servicio, se ha procedido del mismo modo considerando una inercia eficaz del panel según los datos del fabricante y comprobando la deformación máxima en el centro de la barra. Tal como establece el Código Técnico de la Edificación, se ha considerado el factor $k_{\text {def }}$ en las deformaciones para considerar la fluencia propia de la madera y se ha obtenido una flecha máxima de $13,81 \mathrm{~mm}$, inferior a L/300 (17,66 mm). 


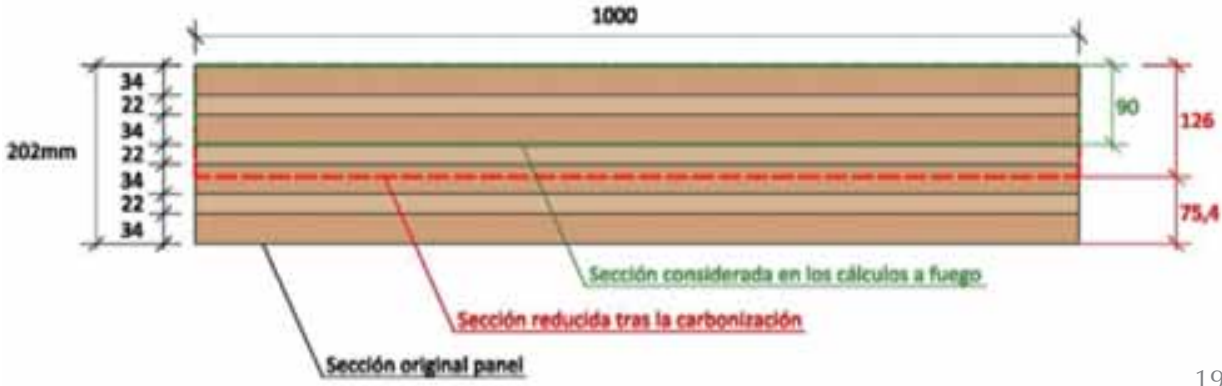

Deformación máxima admisible (ELS) $=$ $\mathrm{f}=\mathrm{L} / 300=5,3 / 300=17,66 \mathrm{~mm}$

Deformación máxima en la combinación de acciones pésima (ELS) $=$ $\mathrm{f}=5 / 384 \cdot \mathrm{Q} \cdot \mid 4 /$ (E.lefectiva) $=$ $5 / 384 \cdot 8,38 \cdot 5,34 /(12.000 \cdot 495.590 .000)=$ $13,81 \mathrm{~mm}$

En el caso de la comprobación accidental ante incendio, La solución adoptada garantiza las estabilidades frente al fuego de 90 minutos necesarias en edificios de pública concurrencia $\left(5 \mathrm{kN} / \mathrm{m}^{2}\right)$, con el espesor propio de los paneles de forjado. A partir de este tiempo se ha determinado una profundidad de carbonización según los criterios establecidos por el Código Técnico de la Edificación en su Documento Básico SE-I, correspondiente a 75,4 $\mathrm{mm}$ de profundidad de carbonización. Tal como se explica en el gráfico adjunto, en el cálculo tan sólo se han considerado aquellas capas que no han sido afectadas, aunque sea parcialmente, por dicha carbonización (Figura 19).

Tensión resistente a fuego: $f, m, d, f i$ $\mathrm{f}_{\mathrm{m}, \mathrm{d}, \mathrm{fi}}=\mathrm{k}_{\text {mod' }} \mathrm{fi} \cdot \mathrm{kfi} \cdot\left(\mathrm{f}_{\mathrm{m}, \mathrm{k}} / \gamma \mathrm{m}, \mathrm{fi}\right)=1 \cdot 1,15 \cdot$ $(24 / 1)=27,6 \mathrm{~N} / \mathrm{mm}^{2}$

Momento de diseño:

$\mathrm{Md}=\mathrm{Q}^{2} / 8=5,51 \cdot 5,32 / 8=19,35 \mathrm{kNm}$

Tensión de diseño (FUEGO)

$\mathrm{M} / \mathrm{W}=19,35 \cdot 106 \mathrm{kNm} / 1215905 \mathrm{~mm}^{3}=$ $15,91 \mathrm{~N} / \mathrm{mm}^{2}$

Los resultados obtenidos según los criterios anteriores, nos indican que la placa se encuentra básicamente limitada por la flecha máxima en el centro de la viga. Mientras que la sección considerada se encuentra al límite en cuanto a Estados Límites de Servicio, el coeficiente de aprovechamiento ante la combinación pésima de Estados Límites Últimos y Situaciones Accidentales (Fuego) todavía es, en algunas situaciones, inferior al $50 \%$ de la sección.

En el encuentro con el muro, el apoyo metálico debe protegerse mediante perlitavermiculita de $30 \mathrm{~mm}$.
A nivel de cumplimiento de normativa frente a ruido aéreo (10), los paneles contralaminados, garantizan un aislamiento de 39 $\mathrm{dB}$, por lo que, para cumplir con los requerimientos exigidos, la solución final consiste en (Figura 20): pavimento de linóleo $4 \mathrm{~mm}$, tablero de madera aglomerada de densidad $600 \mathrm{~kg} / \mathrm{m}^{3} 22 \mathrm{~mm}$, lana de Roca Rocksol-E 52550 mm sumados al panel de madera contralaminada de densidad 500 $\mathrm{kg} / \mathrm{m}^{3} 204 \mathrm{~mm}$.

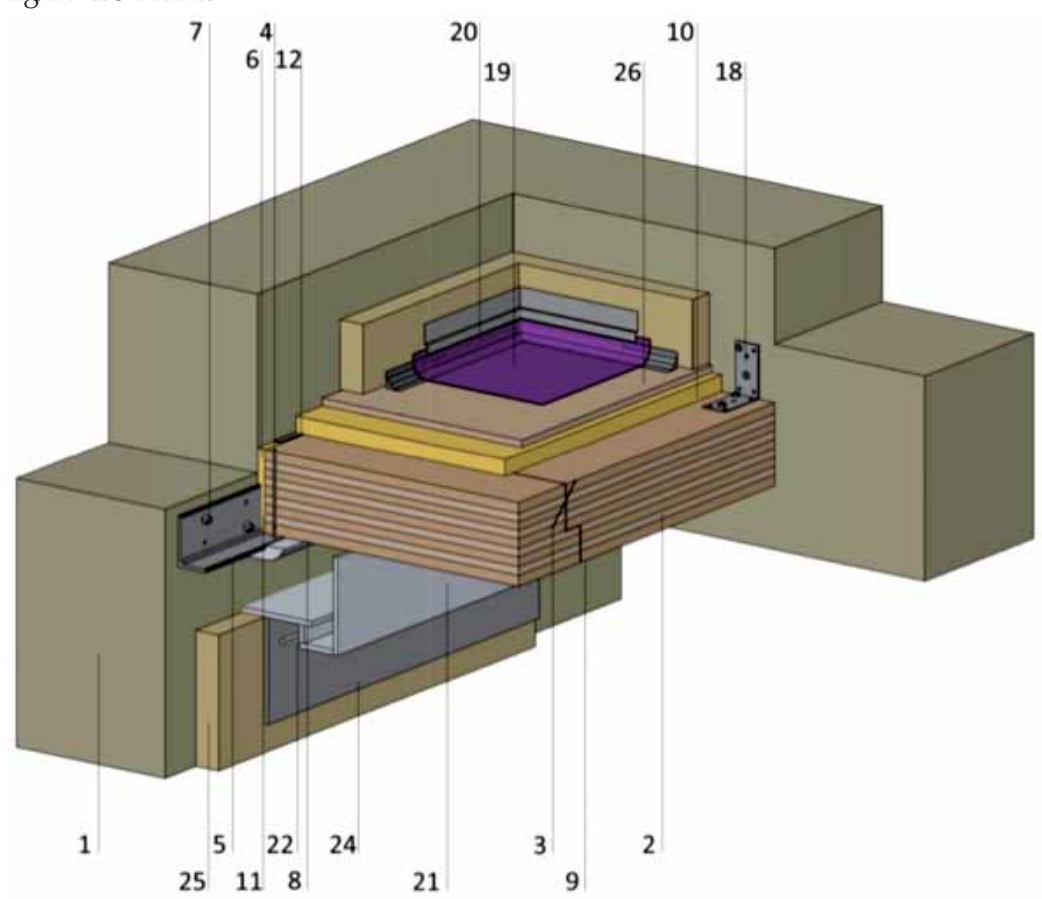

Elementos existentes:

1. Muro de fábrica de ladrillo macizo o piedra

Elementos de proyecto:

2. Panel de madera contralaminada KLH e min. 204mm

Eig0

3. Junta de panel: tirafondo $5 / 1601 \mathrm{c} / 20 \mathrm{~cm}$

4. Unión panel-perfil: pasador autotaladrante SFS WS-T Ø7

4. Union pa

5. Perfil $L$ 150.90.10 galvanizado

6. Retacado con mortero de resinas

7. Anclaje en muro $\mathrm{c} / 20 \mathrm{~cm}$ a tresbolillo: HIT RE500+Varilla

HAS-E M120

8. Proyección de perlita-vermiculita e min. $3 \mathrm{~cm}$ El 90

9. Tratamiento de madera con aceite mineral de alta pureza,

reacción al fuego $\mathrm{Bs} 3, \mathrm{dO}$

10. Panel de lana de roca de alta densidad, e=50

11. Relleno con llana de roca, e min. $35 \mathrm{~mm}$ El 90

12. Sellado intumescente Intumex

18. Escuadras AG T\&T $8025 n^{\circ} 3$ colocadas $\mathrm{c} / 1 \mathrm{~m}$, ancladas

a los muros mediante HIT RE 500 + varillas HAS M10

19. Pavimento de linóleum e 2,5mm

20. Zocalo de media caña y remate de aluminio

21. Cajeado de falso techo de yeso laminado

22. Linea fluorescente

24. Trasdosado de yeso laminado

25. Aislamiento de lana de oveja $e=8 \mathrm{~cm}$

20 26. Panel de aglomerado de particulas
19. Sección del forjado de panel de madera contralaminada donde se identifican los 75,4 mm de carbonización de la sección durante 90 minutos. La sección considerada en el cálculo a incendio es de $90 \mathrm{~mm}$.

20. Detalle constructivo donde se especifica la conexión del forjado a los dos muros. Se identifican los diferentes materiales de acabado del conjunto. 
21. Esquema del proceso de montaje de los paneles de madera contralaminada, utilizando los forjados superiores como elemento resistente.

22, 23, 24 y 25. Entrada de los paneles de madera por la ventana mediante la grúa de obra. En el interior del edificio se trasladan y colocan las piezas gracias al puente grúa instalado provisionalmente en cada sala en el forjado superior ya consolidado.
El resultado del cálculo de aislamiento para esta solución constructiva es:

$R \mathrm{w}=55 \mathrm{~dB}$, garantizando el aislamiento a ruido aéreo de $55 \mathrm{~dB}$ exigido entre recintos de distintas unidades de uso, entre recinto de actividad y recinto protegido.

$\mathrm{Ln}, \mathrm{w}=65 \mathrm{~dB}$, cumpliendo con el máximo aislamiento a ruido de impacto de $65 \mathrm{~dB}$ exigido.

Hay que tener en cuenta que el valor indicado para el aislamiento es un cálculo en base a los valores de aislamiento específicos de cada material. Según datos del fabricante, los valores aportados pueden penalizarse de 4 a $10 \mathrm{~dB}$, siempre dependiendo de las transmisiones laterales que existan y de la calidad de la puesta en obra de esta solución.

\section{EJECUCIÓN DE LA CONSOLIDACIÓN ESTRUCTURAL DE FORJADOS}

Uno de los retos más importantes de la propuesta es desplazar los paneles prefabricados de madera por el interior del edificio existente. Las dimensiones de los paneles más grandes son de 1,2 $\mathrm{m}$ de ancho por 6,5 $\mathrm{m}$ de longitud con un espesor de $245 \mathrm{~mm}$ y peso aproximado de $900 \mathrm{Kg}$. El principal éxito de la aplicación es haber conseguido este propósito gracias a la utilización de toda una serie de medios auxiliares que han permitido desplazar, girar, elevar y colocar paneles de importantes dimensiones y pesos de una manera sencilla y sin esfuerzo físico humano relevante, aprovechando los propios paneles de madera contralaminada (Figuras 21, 22, 23, 24 y 25).
Todos los paneles llegan a obra hechos a medida. Aunque en caso necesario, el panel de madera permite ser cortado y perforado en obra, facilitando el ajuste del elemento prefabricado a irregularidades o imprevistos propios de una obra de rehabilitación o el paso de instalaciones de forma sencilla. Dado que la intención es dejar visto el panel de madera contralaminado, las instalaciones horizontales se pasaran por unos cajones laterales que las ocultan junto al perfil ignifugado que soporta el panel (Figura 20).

El montaje, totalmente en seco, evita cualquier aportación de humedad a los elementos estructurales de la edificación existente y a la vez permite la modificación de los paneles de los forjados durante la obra o en su vida útil sin generar vibraciones ni sobreesfuerzos en el global de la estructura del edificio. Permite plantear a largo plazo la reversibilidad de la intervención y la recuperación íntegra del material de forjado para el reciclaje minimizando el impacto de los residuos de derribo.

Primero se ejecutó los forjados de cubierta y el de la planta inferior, permitiendo garantizar la estanqueidad del edificio. Este primer forjado se colocó con grúa de obra y nos proporcionó garantías estructurales para poder colgar en cualquier punto del mismo los perfiles, guías y poleas necesarios para la colocación del forjado de la planta inmediatamente inferior. De esta forma las cargas generadas por el movimiento de los paneles se transmiten a forjados ya consolidados, o forjados originiales en buen estado, garantizando la seguridad en la ejecución de los trabajos (Figura 26 y 27).

\section{Esquema de colocación de paneles de forjado}
Subministro por grua
colocación con puente grua
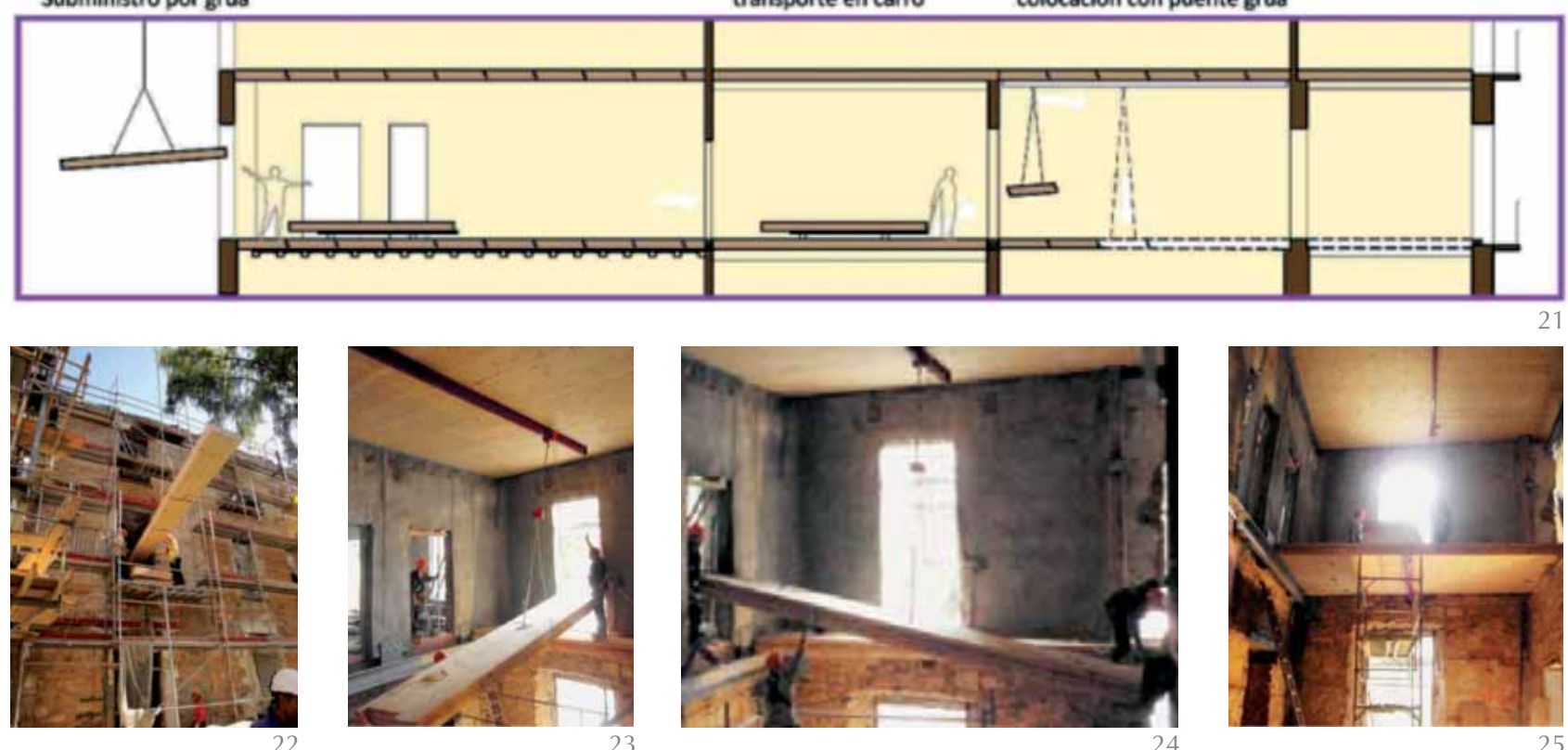

21 
El mecanismo de conexión entre paneles y con los perfiles de apoyo ya anclados a los muros, se realiza mediante tornillería específica de estructuras de madera: tirafondos 5/160 $1 \mathrm{c} / 20 \mathrm{~cm}$ en la unión entre paneles y pasadores autotaladrantes SFS WS-T diámetro $71 \mathrm{c} / 60 \mathrm{~cm}$ en la unión panel con perfil. Esta tornillería es colocada rápidamente por un único operario mientras se realiza la preparación y aproximación de los siguientes paneles, quedando el refuerzo finalizado de manera definitiva (Figuras 28 y 29).

En relación a los forjados existentes, los que se han conservado por su buen estado, han quedado libres de cualquier función portante más alla de aguantar su propio peso. Los que no se han conservado, se eliminaban al mismo tiempo que se ponían las placas para garantizar el arriostramiento del edificio durante la ejecución de la obra.

Todo el sobrepeso de los pavimentos de mosaico hidráulico y relleno de los senos, en algunos casos de hasta $40 \mathrm{~cm}$, se han eliminado para poder realizar el tratamiento fungicida de toda la madera por inyección desde la parte superior siendo así más efectiva la impregnación de toda la madera y cumpliendo lo que establece el CTE. Sobre los forjados existentes conservados y aligerados, se ha vertido una capa de $3 \mathrm{~mm}$ mínimo de perlita-vermiculita con malla de fibra de vidrio intermedia que consolida el conjunto, y a su vez garantiza una estabilidad al fuego de 90 minutos que permite proteger los perfiles metálicos donde apoyan los paneles de madera contralaminada.

El traslado de una solución de prefabricación a la rehabilitación ha permitido reducir el tiempo de ejecución considerablemente, acercándolos a los de la obra nueva. La duración total de la obra ha sido de 8 meses, teniendo en cuenta que la mayor parte de los trabajos estructurales se han destinado a derribo, excavación arqueológica y refuerzo de cimentaciones y muros portantes. El tiempo de montaje efectivo de los forjados ha sido inferior a los 2 meses $\left(2.000 \mathrm{~m}^{2}\right)$, aspecto a remarcar conociendo los condicionantes específicos del edificio, que consta de 4 plantas con espacios completamente irregulares. En el global de la obra, el rendimiento total de colocación de la madera contralaminada ha sido de 5,7 $\mathrm{m}^{2} /$ hora con la participación de 4 operarios. Con cualquier sistema alternativo existente en el mercado habría sido muy difícil cumplir con plazos tan ajustados, ya que las soluciones más comunes se basan en la utilización del hormigón, que necesita un tiempo de preparación (apeos, encofrados y armados) $y$, una vez vertido, un tiempo de fraguado que garantice sus capacidades

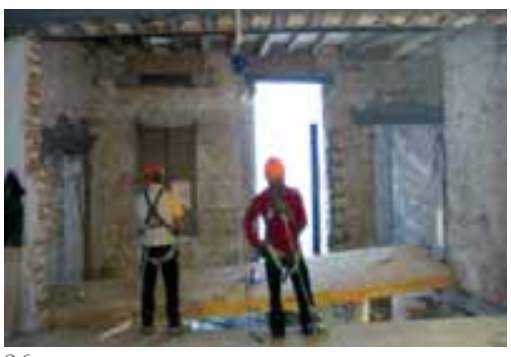

26
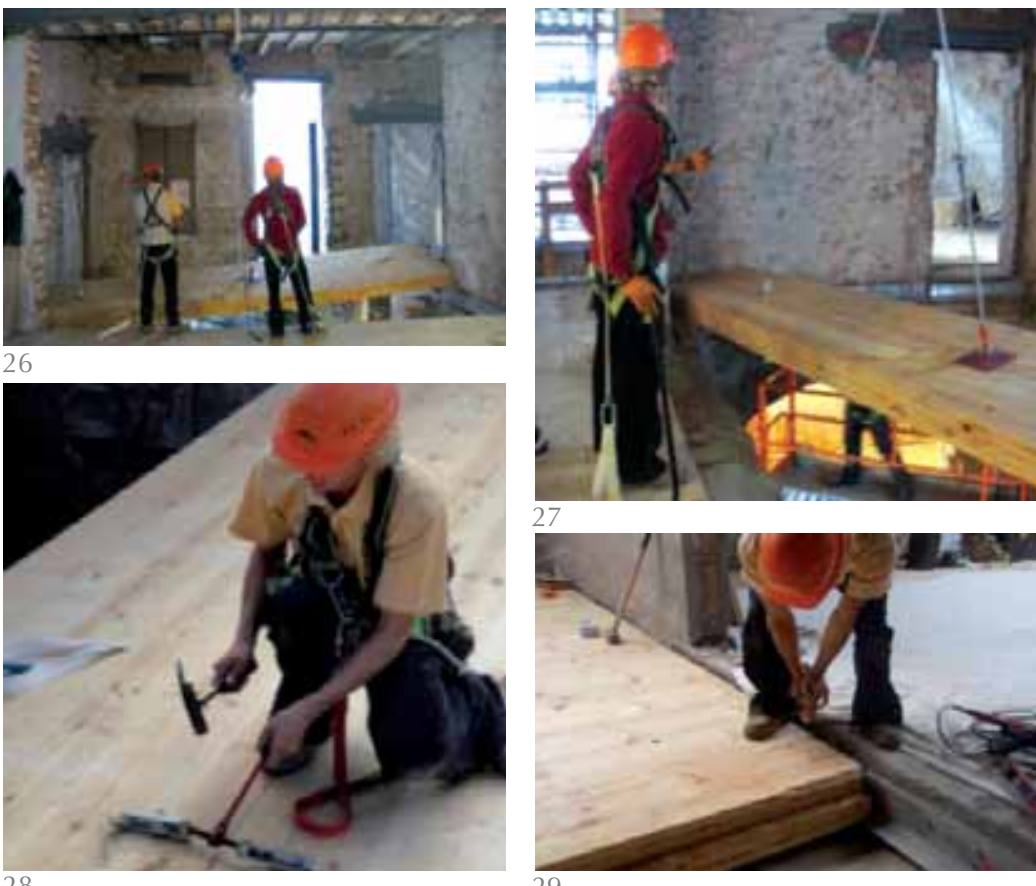

portantes, que habrían supuesto 5 meses de ejecución de forjados como mínimo. Además, los sistemas de encofrado y apeo interfieren en el resto de trabajos de la obra, demostrando que la reducción del tiempo de montaje se duplica en rendimientos y reduce las situaciones que debilitan estructuralmente el edificio.

La solución mejora la seguridad en obra, dado que la facilidad para atornillar sobre el panel de madera permite asegurar siempre las líneas de vida y arneses. Una vez colocado el panel, las bridas de manipulación del mismo, sirven de punto de anclaje para el arnés del operario y el panel mismo ofrece una superfície de trabajo segura en la cara superior, por lo que no hay riesgo de caída de material sobre el trabajador.

\subsection{Validación de las bases teóricas mediante ensayos de carga}

La realización de pruebas de carga estáticas y dinámicas realizadas en la obra en diferentes tramos de forjados y en los ensayos de rotura hechos en el laboratorio (Figura 30), nos han permitido verificar el cumpli-

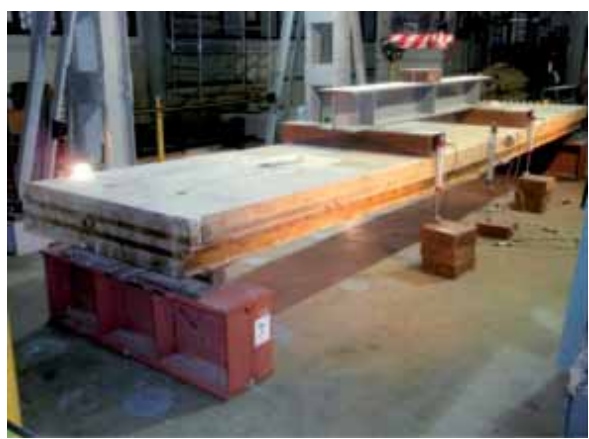

30
26 y 27 . Colocación de los panales de madera contralaminada sobre puntos de anclaje del forjado superior existente en buen estado de conservación.

28 y 29. Una vez situado cada panel se procede a su ajuste con los gatos y anclajes.

30. Pruebas de carga de los paneles de madera contralaminada en el laboratorio de la UPC. Resistencia de cálculo a flexión según DITE del fabricante: $24 \mathrm{~N} / \mathrm{mm}^{2}$ Dimensiones de la pieza ensayada: $5500 \times 1200 \times 248$ mm Resultado: carga máxima: 367 kN, deformación: $87 \mathrm{~mm}$ y resistencia a flexión: $298 \mathrm{~N} / \mathrm{mm}^{2}$. 
31. Pruebas de carga de los forjados en la obra de $8,5 \mathrm{kN} / \mathrm{m}^{2}$ en el tercio central del vano.

32. Planta del funcionamiento mecánico del conjunto donde se grafían los muros de ladrillo de $150 \mathrm{~mm}$ reforzados mediante gunitado.

33. Detalle constructivo donde se especifica la continuidad del armado del gunitado a través de los forjados existentes.

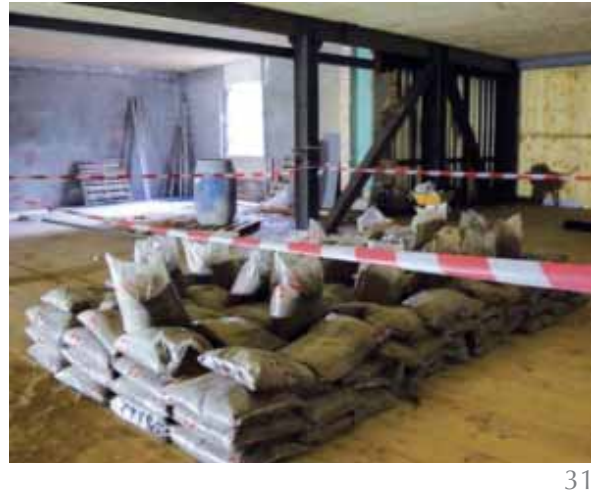

miento de los requisitos resistentes establecidos en los cálculos (11). Dentro de estos ensayos se engloban las pruebas de carga estáticas y dinámicas. Las pruebas de carga estáticas han consistido en la colocación de una sobrecarga de $8,5 \mathrm{kN} / \mathrm{m}^{2}$ en el tercio central del vano, obteniendo una flecha de alrededor de 1/1000 de la luz coincidente con los cálculos realizados (Figura 31).

Las pruebas de carga dinámicas se han realizado en 3 espacios diferentes del edificio. En relación a las prescripciones que establece el Código Técnico de la Edificación,

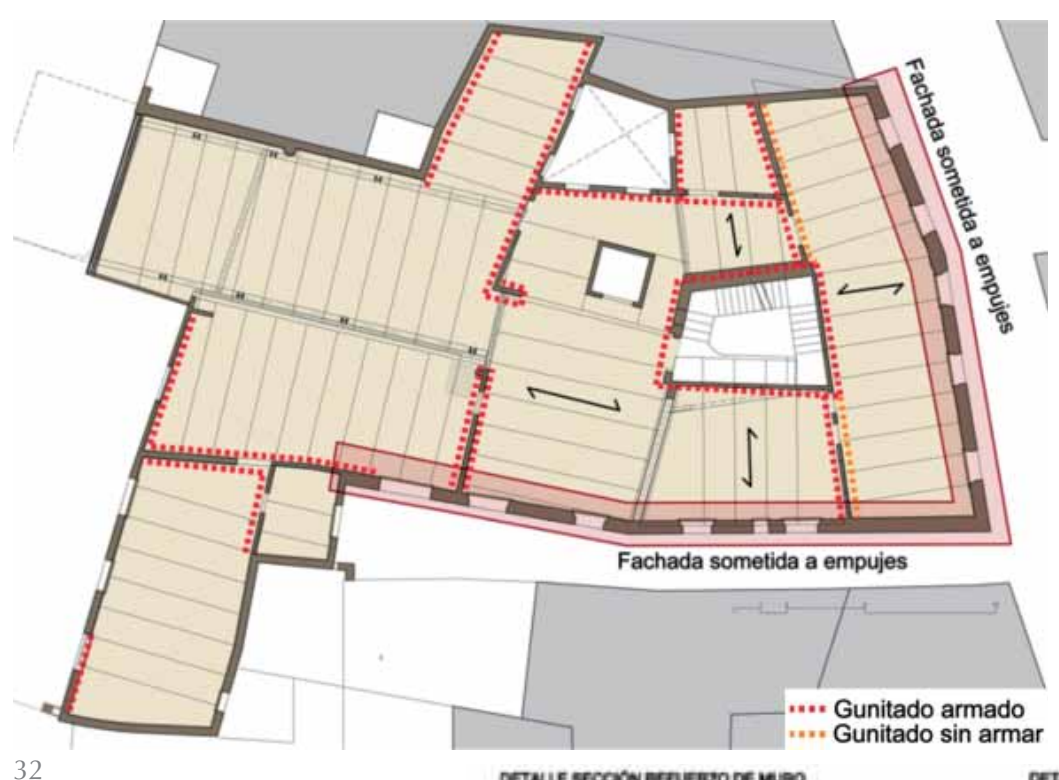

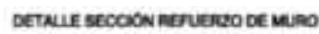
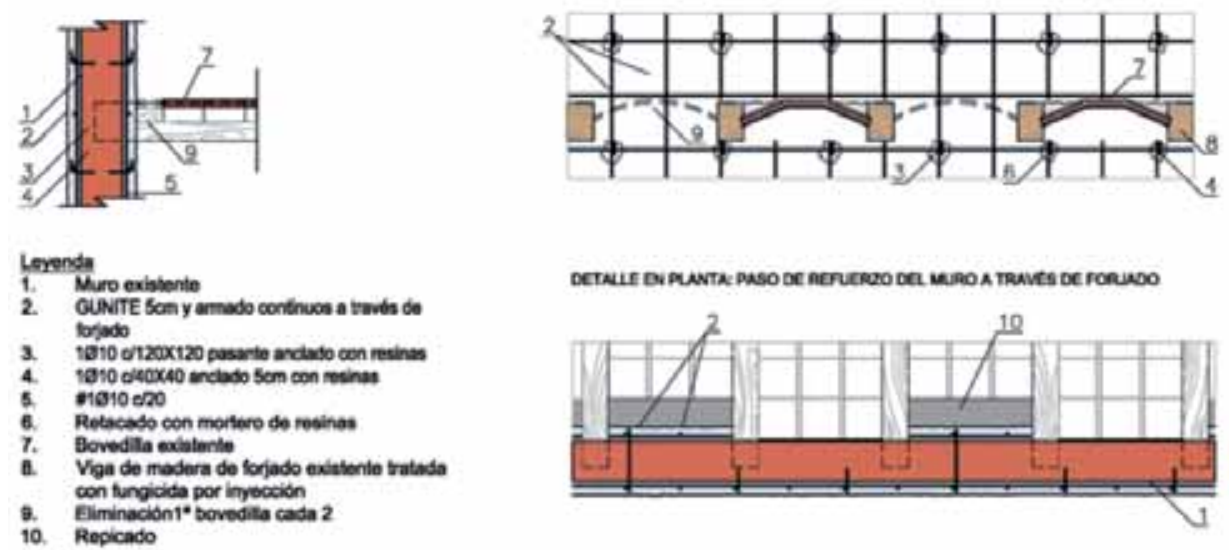

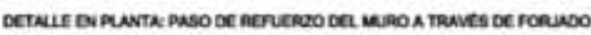

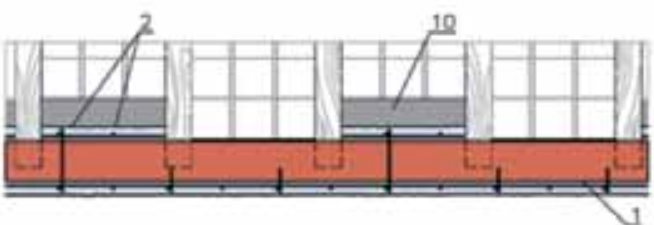

los valores de frecuencia de vibración obtenidos son inferiores a los requeridos por la tipología del edificio.

\section{TRABAJOS DE CONSOLIDACIÓN EN MUROS Y ARCOS}

\subsection{Consolidación estructural de muros}

La consolidación de la escalera patrimonial ha consistido en el grapado de las esquinas inconnexas así como el posterior refuerzo de los 4 tramos de muros de $15 \mathrm{~cm}$ de ladriIlo macizo gunitando el perímetro exterior para aumentar su rigidez e incrementar su capacidad de actuar como un núcleo rígido que garantice la estabilidad a los empujes horizontales que generan las bóvedas a la catalana de la escalera (Figura 32). Para garantizar la continuidad entre plantas del armado del gunitado, de los forjados existentes conservados se han vaciado algunos tramos de bovedillas en contacto con el muro a reforzar (Figura 33). El hecho de gunitar por la cara exterior fue una decisión condicionada a la posible aparición de serigrafiados o pinturas de valor patrimonial por el interior de los muros de la escalera y para no reducir el ancho útil de $1 \mathrm{~m}$ de los tramos de la escalera patrimonial, ya de por sí muy ajustados.

Una vez consolidado el núcleo portante, se procedió al refuerzo de la bóveda mediante la realización de una capa de compresión de hormigón armado de $70 \mathrm{~mm}$ de espesor, conectada a los muros, que permite retirar los refuerzos metálicos ortopédicos colocados en el pasado siglo. Para la verificación de la solución, se retiró el refuerzo en un tramo de bóveda, y se realizó una prueba de carga de $6 \mathrm{kN} / \mathrm{m}^{2}$ durante 24 horas para comprobar la deformación que fue despreciable. Posteriormente, se retiraron los refuerzos metálicos en el resto de tramos, recuperando el aspecto liviano de la escalera de bóveda a la catalana.
DETNIE NINDO MUTO RETORUDO 
Los muros de piedra y tapia en general presentan un buen estado y su evaluación técnica permite que sigan trabajando (12).

En cambio la estructura vertical de paredes de fábrica de ladrillo macizo, en algunos casos ha sido preciso gunitarlas con armado ya que al eliminar la tabiquería existente resultaban excesivamente esbeltos o largos. Este es el caso de la fachada del Jardín Romántico en planta primera y segunda que tiene 12 metros de longitud y $15 \mathrm{~cm}$ de grosor sin trabas perpendiculares. Para garantizar su capacidad de trabajo a tracción se procedió a proyectar un gunitado armado previo grapado de grietas con varilla de acero inoxidable.

En la zona del nuevo acceso que se genera en el edificio por la nueva plaza 8 de marzo no se podía afectar el espacio de las dos pilastras romanas del acueducto. Este hecho obliga a hacer un voladizo de $2,5 \mathrm{~m}$ para salvar las estructuras arqueológicas. Por otro lado, este espacio, comprendido entre los pilares del acueducto, se encontraba dividido por una pared parteluz, y con la voluntad de conseguir un vestíbulo diáfano, se optó por eliminar dicho muro, generando un espacio de 6,5 metros de luz. A la vez, los muros que rodean este espacio, en los cuales se debía apoyar el nuevo forjado, tenían su estabilidad muy condicionada. En un lado, se trataba de una pared medianera, de propiedades heterogéneas y con dificultad para obtener información. En el extremo opuesto, el muro en planta baja se encontraba debilitado por un arco del siglo XIII cortado por un pozo del s.XIX hasta planta principal; en las plantas superiores, el apoyo se convertía en un muro de ladrillo de $15 \mathrm{~cm}$ de espesor de más de 12 metros de longitud.

Por todos los motivos expuestos, la solución estructural en este ámbito del acueducto romano se tubo que realizar una sustitución funcional de los apoyos, mediante una nueva estructura metálica independiente soportada por unos pórticos metálicos sobre unos encepados con tres micropilotis cada uno. Cabe destacar que de todo el edificio este espacio es el único lugar donde no trabaja la estructura vertical original.

\subsection{Consolidación estructural de arcos}

La consolidación estructural de los arcos de planta baja ha requerido un estudio individualizado caso a caso debido a la heterogeneidad de sus características estructurales y sus lesiones. Encontramos dos tipologías básicas de arcos: los de sillares de piedra del siglo XIII, y los arcos de ladrillo del XIX (Figura 4).

\section{Arcos s.XIII.}

Los arcos medievales, según la diagnosis efectuada, presentaban diferentes estados de cargas y lesiones. La prioridad adoptada en este tipo de arcos es no realizar refuerzos metálicos para poder mantener el aspecto original en todos los arcos, y favorecer los sillares vistos.

El arco 1, situado en el vestíbulo de la calle Ripoll, es el mayor arco descubierto en las labores de repicado y de derribos menores en planta baja. Se trata de un arco de 3,30 metros de altura y 7 metros de luz, que denota una gran crujía de acceso, propia de una tipología de palacio medieval hoy difícilmente identificable a causa de todas las intervenciones que se han ido realizando a lo largo de los siglos. El arco se encuentra muy desfigurado, ya que en la parte central los sillares habían sido substituidos por ladrillos, e incluso tenía un pequeño dintel metálico coincidente con el paso de la escalera principal. La solución adoptada recupera visualmente el perfil de $7 \mathrm{~m}$ de luz del arco original mediante 2 parejas de perfiles HEB100 curvados sobre una pletina de $8 \mathrm{~mm}$ de espesor, soldados entre sí (Figuras 34,35 y 36). Se opta por esta solución dada la imposibilidad de recuperar la imagen de arco de sillares original. A su vez, el refuerzo se hace necesario para soportar las tres plantas de sobrepeso que actualmente descansan sobre el arco.

El arco 2, de 3,30 metros de altura y 4,45 metros de luz, presenta grietas y fisuras por exceso de carga. La reparación consiste en una liberación de cargas mediante el cambio de dirección de los forjados de las plantas superiores. Finalmente se sellan las grietas mediante mortero de cal.

El arco 3, de 3 metros de altura y 3 metros de luz, se reforzó en el s. XVIII mediante un arco de obra de fábrica por la cara inferior. No presentaba lesiones importantes, porque soporta únicamente el forjado de la planta superior, ya que en el resto de plantas los forjados cargan en la dirección perpendicular. Aun así, el arco se ve beneficiado de la disminución del peso de los nuevos forjados.

El arco 4, de 2,30 m de altura y 5,45 metros de luz, se encontraba desconfigurado debido a una actuación del siglo XIX en la cual se construyó un pozo que conectaba la planta principal con la planta baja, partiendo el arco por la mitad. A nivel de cargas, también presentaba un exceso de carga ya que soportaba los forjados de los cuatro forjados superiores. La actuación en este caso fue de sustitución funcional 


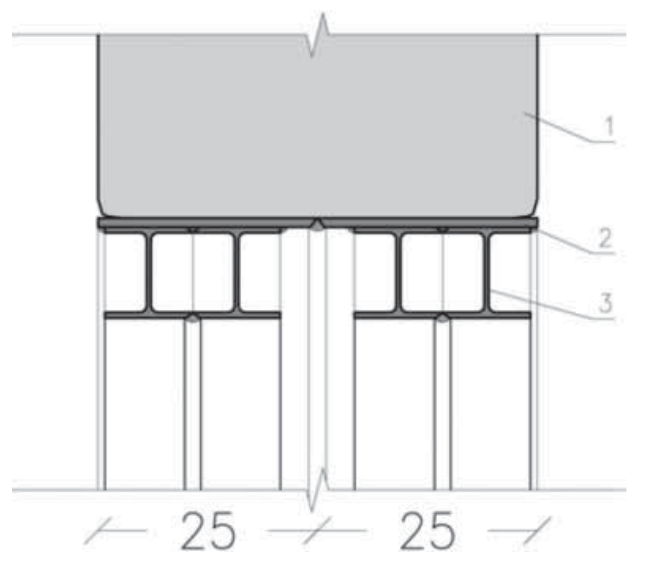

Leyenda:

1. Arco existente

2. Pletina curvada $e=8 \mathrm{~mm}$

3. HEB-100 curvado

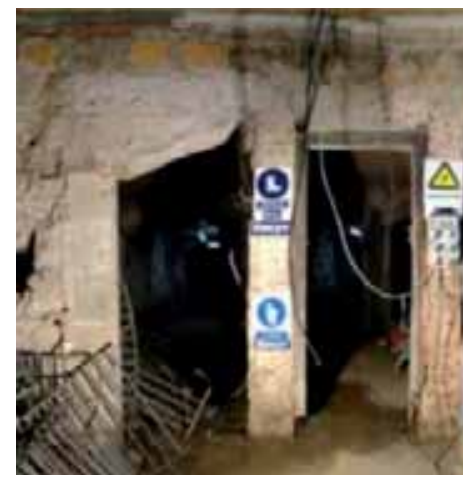

34, 35 y 36. Detalle constructivo del refuerzo del arco medieval de piedra de $7 \mathrm{~m}$ de luz en el vestíbulo de acceso desde la calle Ripoll. Imagen previa al refuerzo y una vez finalizado.

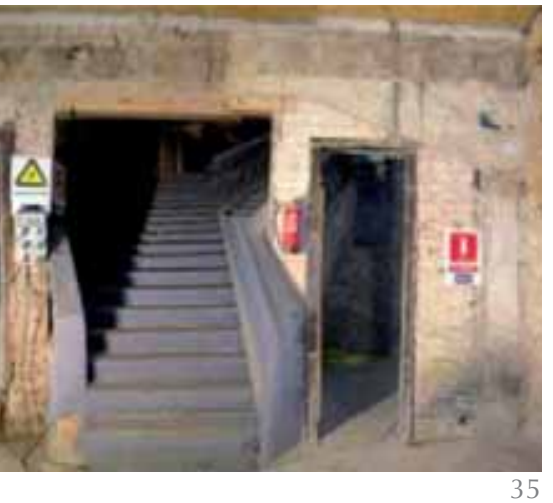

mediante la construcción de un pórtico metálico que soporta los nuevos forjados, liberando el arco de las cargas, de manera que ahora soporta un único piso. Esta actuación se detalla en el apartado 5.4.

El resto de arcos medievales, como el 5 y 6 , no presentaban graves lesiones, gracias a que su estado de cargas era correcto y únicamente se efectúa la consolidación de las juntas con mortero de cal.

\section{Arcos del siglo XVIII-XIX.}

En cuanto a los arcos de obra de fábrica, corresponden o bien a arcos medievales que fueron substituidos, o bien a las actuaciones de liberación de la planta baja, debidas a la actividad de una imprenta con necesidad de grandes espacios en el siglo XIX.

El criterio en este caso es consolidar los arcos, diferenciándolos de los arcos medievales, que se dejan repicados con los sillares vistos. Esto permite utilizar soluciones de refuerzo metálico, ocultos bajo el futuro revestimiento.

El arco 7 sufre en el siglo XIX la colocación de un pilar de fundición en el centro. Esta intervención lo despoja de su condición de arco y deja de trabajar como tal, concentrando las cargas en el punto medio, que se ve profundamente agrietado por el esfuerzo cortante que se genera. Se considera oportuno mantener el pilar de

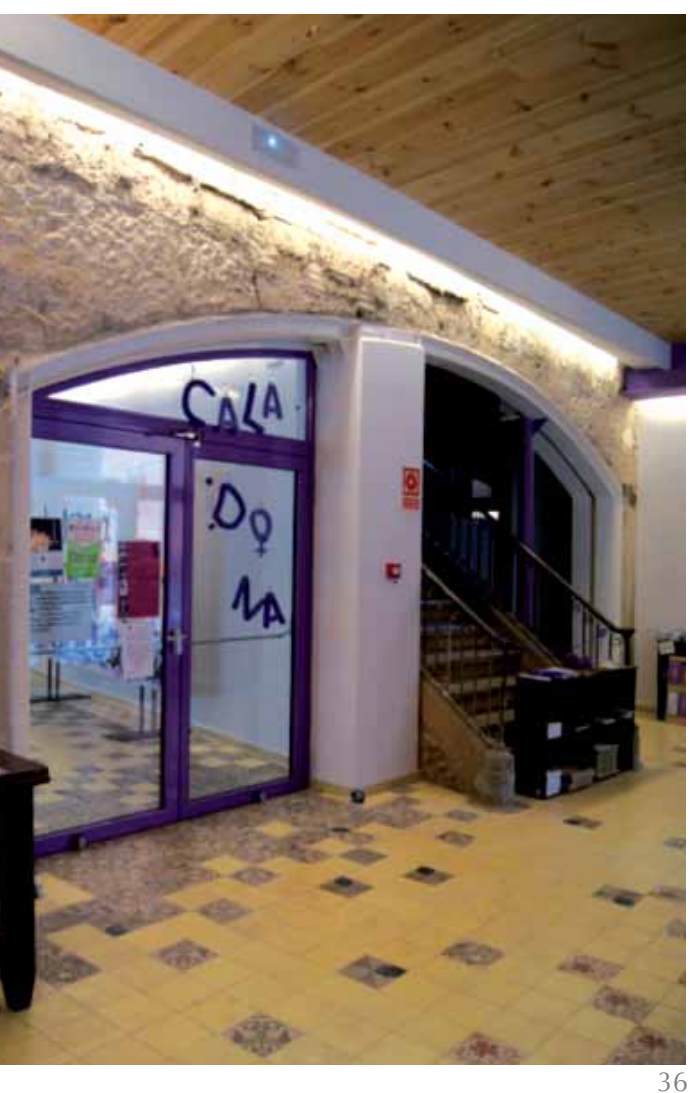

fundición como muestra de intervención histórica. El refuerzo del arco consiste en la colocación de una pletina metálica por la cara interior del arco, fijada mediante tacos químicos y retacado mediante mortero Sika Monotop 620.

El arco 8.1, de 3,41 metros de altura y 3,15 $\mathrm{m}$ de luz, y el arco 8.2, de la misma altura y $2,75 \mathrm{~m}$ de luz, se encontraban muy afectados debido al exceso de cargas. Resultaba imprescindible reforzar el arco para aumentar su capacidad portante puesto que, aun disminuyendo cargas de forjados, los arcos de ladrillo no tenían suficiente capacidad portante según el criterio de la normativa actual. La solución en este caso se realiza mediante un empresillado con una UPN-300 a cada lado del arco, sujetas ambas mediante pasadores. En el caso del arco número 10, de semejante lesión, se realizó también un empresillado pero más sencillo, ya que la luz del arco era mucho menor así como menores eran también la exigencia portante.

Los arcos 9.1, de 3,25 metros de altura y 2,75 m de luz; y 9.2, de 3,10 metros de altura y 1,35 metros de luz; eran los más afectados por grietas y cargas. Su estado no permitía que siguieran soportando las cargas de forjados superiores, así que para mantener la imagen de la sala, rodeada en tres lados por arcos, la solución consiste en realizar un dintel metálico formado por una doble IPN240 por la parte superior del arco, que libere a la estructura existente 
de su función portante. Los arcos quedan colgados de los nuevos perfiles metálicos mediante anclajes roscados y fijados con resina.

El arco 10, situado en la fachada de la calle Ripoll, es el único arco de obra nueva. La recuperación de las aberturas originales de planta baja en esta fachada permite uniformizar la imagen a nivel compositivo. Se ha formalizado mediante un doble arco cerámico de ladrillos macizos. Finalmente el arco 11, de 3,17 metros de altura y 4,85 metros de luz, que presentaba profundas grietas, fue liberado de cargas, al cambiar la dirección del forjado superior y consolidado mediante el cosido de grietas y el gunitado de las jambas de ladrillo.

\subsection{Consolidación de cimientos}

La diagnosis estructural del edificio no indicaba fallos en la cimentación, aunque el estudio geotécnico mostraba una baja resistencia mecánica del terreno con valores de compresión simple entre 0,96 y 1,35 $\mathrm{kg} / \mathrm{cm}^{2}$ (13), recomendando la realización de una cimentación profunda. Por ello, se hizo una primera actuación consistente en eliminar cargas excesivas en el edificio, eliminando tabiquerías de ladrillo y aligerando forjados conservados suprimiendo pavimentos hidráulicos y rellenos. Estas actuaciones sumadas a la solución de forjado adoptada permiten aligerar parte del peso del edificio y compensar parcialmente el aumento de las sobrecargas de uso (pública concurrencia) permitiendo reducir la cimentación profunda a la mitad. La solución definitiva consiste en micropilotes a 12 metros de profundidad separados 1,5 metros y arriostrados por una losa de $25 \mathrm{~cm}$ de canto conectada a los muros portantes.

El desnivel entre salas existente en la planta baja era de hasta un metro y medio. Para poder cumplir la normativa de accesibilidad se tubo que realizar una excavación con sus implicaciones de trabajos arqueológicos que en algunos casos dejaba los muros descalzados y se procedió a recalzarlos de forma intercalada.

En las excavaciones arqueológicas realizadas durante la fase de consolidación estructural, se encontraron nuevas estructuras en la cota de planta baja. Se descubrió una escalera no documentada anteriormente que arranca en un extremo de la planta baja y desciende hacia una posible fresquera situada bajo el jardín romántico. Se modificó la losa de cimentación para dejar registrable la escalera y facilitar futuros trabajos de arqueología que permitan averiguar a dónde conduce.

\section{CONCLUSIONES}

La rehabilitación del edificio de Ca la Dona en Barcelona, es una muestra más de la complejidad a la que se enfrentan los profesionales a la hora de recuperar un edificio existente para un nuevo uso. El conocimiento exhautivo del edificio que dan los estudios históricos, arquelógicos, así como la diagnosis previa son una herramienta básica e indispensable para establecer los criterios de la intervención a realizar. También ha sido imprescindible, un nuevo valor, el del trabajo participativo, en este caso con las usuarias de Ca la Dona, compartiendo el conocimiento del edificio, reflexionando en común sobre el mismo para definir una propuesta de intervención sostenible y a su vez respetuosa con los valores intrínsecos del edificio.

La madera contemporánea utilizada en el refuerzo integral o la sustitución funcional de forjados leñosos es una de las claves para la incorporación de criterios sostenibles en la rehabilitación de edificación en los próximos años. La madera es un material, que gracias a su bajo impacto ambiental, flexibilidad, ligereza y reciclabilidad es fundamental en la búsqueda de nuevas soluciones. La gran variedad de productos derivados de la madera existentes actualmente permite empezar a incorporar soluciones de refuerzo integral de forjados históricos con madera, mejorando la compatibilidad con el resto de elementos resistentes del edificio rehabilitado. Algunos de estos productos, como la madera microlaminada, los tableros fenólicos o los paneles contralaminados representan una opción innovadora, que ya se ha validado en algunas rehabilitaciones como la el presente artículo explica.

La solución propuesta abre un camino adicional en el ámbito del refuerzo estructural de edificios existentes que garantiza los condicionantes normativos actuales con una solución ligera. A su vez aporta mejoras en los tiempos de ejecución de obra y en la seguridad de la misma. También es especialmente importante la posibilidad de respetar la estructura original del edificio o los hallazgos arqueológicos que en él se encuentran, así como la reversibilidad de la propuesta estructural de forjados propuesta en Ca la Dona. 


\section{BIBLIOGRAFÍA}

(1) Nuere, E.: "Madera, en restauración y rehabilitación", Informes de la construcción Vol 59, No 506 (2007), pp.123-130.

(2) Esteban, M.; Argüelles, R.; Arriaga, F.; Íñiguez. G.; Bobadilla, I.: "Estado actual de la investigación sobre madera estructural en España", Informes de la construcción Vol 59, No 506 (2007), pp.15-17.

(3) Ripoll, G.; Mas. H. Universidad de Barcelona: "Estudio arqueológico del edificio de la calle Ripoll 25". Documento inédito entregado al Servicio de Arqueología de la Generalitat de Catalunya, Barcelona, 2007.

(4) González, R.; Caballé, F. Veclus SL.: "Estudio histórico-arquitectónico de la finca núm. 25 del carrer Ripoll". Documento inédito entregado al Servicio de Arqueología de la Generalitat de Catalunya, Barcelona, 2002.

(5) Trias, V. Àtics SL.: "Memoria de la intervención arqueológica realizada en la calle Ripoll 25", Documento inédito entregado al Servicio de Arqueología de la Generalitat de Catalunya, Barcelona, 2009.

(6) Monton, J.; Rosell, J.R.. Laboratorio de Materiales. Universidad Politécnica de Catalunya: "Diagnosis de forjados del edificio de Ripoll 25", Documento inédito, Barcelona, 2009.

(7) G. Cangi. Manuale del recupero strutturale e antisismico, p.194, DEI Tipografia del Genio Civile, Roma, 2005.

(8) Linee guida per la valutazione e la riduzione del rischio sismico del patrimonio culturale con riferimento alle Norme tecniche per le costruzioni di cui al decreto del Ministero delle Infrastrutture e dei trasporti del 14 gennaio 2008. p.111-113, Ministero per i Beni e le Attività Culturali, Italia, 2010.

(9) Techniques for the Seismic Rehabilitation of Existing Buildings: FEMA 547, Chapter 22 - Diaphragm Rehabilitation Techniques, Federal Emergency Management Agency, Estados Unidos, 2006.

(10) Código Técnico de la Edificación (CTE), Dirección General de Arquitectura y Política de Vivienda del Ministerio de Vivienda. España, 2006.

(11) Bestraten, S. ; Hormias, E.: "Prefabricación en rehabilitación: El panel de madera contralaminada en el edificio de Ca la Dona". CIMAD 11, 1r. Congreso Ibero-Latinoamericano de la madera en la construcción. Coimbra, Portugal 07-09 Junio 20011. Primer Premio Tafibra a la mejor comunicación.

(12) Bestraten, S. ; Hormias, E.: "Structural criteria for the restoration of rammed earth buildings in Barcelona province". p.269-275. A: Mileto, Vegas \& Cristini (eds). 1st International Conference on Rammed Earth Conservation Restapia, Valencia, Spain, 21-23 June 2012, Taylor \&Francis Group, London, 2012.

(13) López, S.: "Estudio Geotécnico del edificio de la calle Ripoll 25", Documento inédito, Barcelona, 2009. 